\title{
Model of Early Diagenesis in the Upper Sediment with Adaptable complexity - MEDUSA (v. 2): a time-dependent biogeochemical sediment module for Earth system models, process analysis and teaching
}

\author{
Guy Munhoven \\ Dépt. d'Astrophysique, Géophysique et Océanographie, Université de Liège, 4000 Liège, Belgium \\ Correspondence: Guy Munhoven (guy.munhoven@uliege.be)
}

Received: 14 September 2020 - Discussion started: 9 October 2020

Revised: 21 April 2021 - Accepted: 28 April 2021 - Published: 15 June 2021

\begin{abstract}
MEDUSA is a time-dependent one-dimensional numerical model of coupled early diagenetic processes in the surface sea-floor sediment. In the vertical, the sediment is subdivided into two different zones. Solids (biogenic, mineral, etc.) raining down from the surface of the ocean are collected by the reactive mixed layer at the top. This is where chemical reactions take place. Solids are transported by bioturbation and advection, and solutes are transported by diffusion and bioirrigation. The classical coupled timedependent early diagenesis equations (advection-diffusion reaction equations) are used to describe the evolutions of the solid and solute components here. Solids that get transported deeper than the bottom boundary of the reactive mixed layer enter the second zone underneath, where reactions and mixing are neglected. Gradually, as solid material gets transferred here from the overlying reactive layer, it is buried and preserved in a stack of layers that make up a synthetic sediment core.

MEDUSA has been extensively modified since its first release from 2007. The composition of the two phases, the processes (chemical reactions) and chemical equilibria between solutes are not fixed any more, but get assembled from a set of XML-based description files that are processed by a code generator to produce the required Fortran code. 1D, 2D and $2 \mathrm{D} \times 2 \mathrm{D}$ interfaces have been introduced to facilitate the coupling to common grid configurations and material compositions used in biogeochemical models. MEDUSA can also be run in parallel computing environments using the Message Passing Interface (MPI).
\end{abstract}

\section{Introduction}

\subsection{Ocean-sediment exchange schemes: an overview}

Ocean biogeochemical cycle models call upon a variety of schemes of different complexity levels to represent oceansediment exchange fluxes. These can be classified into four major categories (Hülse et al., 2017): (1) reflective boundary conditions; (2) semi-reflective or conservative; (3) vertically integrated dynamic models; and (4) vertically resolved diagenetic models. These categories are similar but not identical to the levels in the classification of Soetaert et al. (2000): categories 3 and 4 respectively correspond to their level 3 and 4 descriptions; category 1 fits their level 2 description, while category 2 generalises the latter.

Reflective boundary conditions are the simplest of these: material reaching the model sea floor (i.e. the deepest layer in the model water column) is unconditionally remineralised (oxidised, dissolved) there. Global mass conservation is obviously guaranteed with this approach, but the approach may be unrealistic in some places: calcite gets dissolved even if the sea floor bathes in waters that are strongly supersaturated with respect to calcite or organic matter oxidised even if oxygen levels are low. This unrealistic behaviour can to some extent be alleviated with the semi-reflective or conservative scheme. Here, only some of the remineralisation products (nutrients, dissolved inorganic carbon, silica, etc.) of the solids reaching the sea floor are returned to the bottom water; the remainder is returned to the surface, mimicking riverine input and once again allowing for global mass con- 
servation. The fraction remineralised can be made to vary in space and time and can also be different for different materials. Carbonate fractions remineralised can e.g. be linked to the degree of saturation with respect to one carbonate mineral or another, and organic carbon fractions remineralised can be linked to the degree of oxygenation of the bottom waters. Both schemes are attractive because of their convenient computational efficiencies. They do not, however, allow us to take into account the complexities of the actual remineralisation pathways of the various biogenic components in the surface sediments, nor can they represent the temporary storage of such materials in the surface sediment or delayed return of nutrients, dissolved inorganic carbon or silica to the ocean bottom waters.

The vertically integrated dynamic category 3 encompasses ocean-sediment exchange schemes that explicitly include a single-box representation of the surface sediment. Mass balances of some, if not all, constituents of this single-layer sediment can be traced. Although termed "vertically integrated" not all of the schemes that fall into this category can be traced back to some actual vertically resolved model that was vertically integrated.

Vertically resolved diagenetic models finally represent the most mechanistically oriented alternative to represent oceansediment exchange fluxes. Such models can take into account the complex interplay between various diagenetic processes (organic matter remineralisation, mineral dissolution or precipitation) and transport pathways (advection, bioturbation, solute diffusion in pore water, bioirrigation, etc.). They solve a set of coupled standard early diagenesis equations (Boudreau, 1997) for solid and dissolved component concentrations, generally in combination with law of mass action equations for chemical equilibria (e.g. for the carbonate system).

Meta-model approaches (Sigman et al., 1998; Dunne et al., 2007; Ridgwell, 2007; Capet et al., 2016), i.e. parametric representations or emulators of comprehensive models, may either fit into the second or the third categories depending on their design. Such emulators generally come as empirical parametric functions, typically derived by fitting selected model outcomes (such as diffusive return fluxes) from large sets of simulation experiments carried out with varying boundary conditions to some expert-chosen empirical parametric functions (Dunne et al., 2007). Another promising venue is the analysis of complex models with approaches based upon system identification theory (see Crucifix, 2012, for an introduction to these methods for the emulation of complete Earth system models (ESMs) and Ermakov et al., 2013, for a pilot application to the coupled ocean carbon cycle-sediment model MBM-MEDUSA; Munhoven, 2007).

The actually required complexity of an adopted oceansediment exchange scheme depends of course on the application made. For short-term experiments (say a few decades to a few centuries) with high-resolution biogeochemical models, carefully calibrated semi-reflective-conservative schemes are generally the only viable but nevertheless perfectly acceptable option. For long-term applications (simulation experiments exceeding several thousand years, i.e. several ocean mixing cycles), vertically integrated or resolved schemes are required for realistic model responses to changing boundary conditions and forcings.

The surface sedimentary mixed layer, where most of the processing of the deposited biogeochemically relevant material takes place, only extends down to about 5 to $15 \mathrm{~cm}$ on global average ( $9.8 \pm 4.5 \mathrm{~cm}$ according to Boudreau, 1994). As a result of the diagenetic processes in action there, strong concentration gradients are generated and sustained: the amplitude of the concentration differences observed over this depth interval may be comparable to those observed in the more than 4 orders of magnitude thicker overlying water column ( $3750 \mathrm{~m}$ on average) - see the oxygen and $\mathrm{pH}$ profile data in Sect. 3.3. A realistic explicit representation of the surface sedimentary environment thus requires a vertical resolution of the same order of magnitude in terms of vertical layers or grid points as the complete water column above it. Typical vertically resolved early diagenesis models present vertical resolutions of the order of 10 to 20 layers (see Table 1). For comparison the water column in GENIE-1, which includes SEDGEM (Ridgwell, 2007; Ridgwell and Hargreaves, 2007), has eight vertical layers; HAMOCC 2s (Heinze et al., 2009) has 10, and the more recent HAMOCC 5.2 (Ilyina et al., 2013a) has 40 layers.

Accordingly, sea-floor sediment modules (category 3 and 4 schemes) are not yet commonplace in global ocean biogeochemical models. Only 4 out of 15 Earth system models of intermediate complexity (EMICs) participating in the EMIC AR5 Intercomparison Project (Eby et al., 2013) are reported to have a sediment module included: Bern3D (Tschumi et al., 2011), DCESS-ESM (Shaffer et al., 2008), GENIE (Ridgwell and Hargreaves, 2007) and UVic 2.9 (Eby et al., 2009); one further participating EMIC, CLIMBER 2, is also routinely used with a sedimentary module included (e.g. Brovkin et al., 2012). Advanced high-resolution models generally call upon category 1 or 2 schemes for their seafloor boundary condition, although there are exceptions. The HAMOCC (HAmburg Model of the Oceanic Carbon Cycle) family of models, whose origins reach back to Maier-Reimer (1984), actually has a long-standing history of explicitly taking sedimentary processes into account. HAMOCC 2 (Heinze et al., 1991) was the first one to get a fully coupled sediment module (Archer and Maier-Reimer, 1994), the oxic-only version of the calcite dissolution model of Archer (1991). Later, it received a purposely developed sediment module (Heinze et al., 1999; Heinze and Maier-Reimer, 1999). Archer et al. (2000) used HAMOCC 2 coupled to the much more complete diagenetic model MUDS (Archer et al., 2002), which considers the sequence of oxic, suboxic (via $\mathrm{NO}_{3}^{-}, \mathrm{FeOOH}$ and $\mathrm{MnO}_{2}$ reduction) and anoxic (via $\mathrm{SO}_{4}^{2-}$ reduction) organic matter remineralisation pathways. Later developments of HAMOCC also included suboxic reminer- 
Table 1. General characteristics of vertically resolved sediment models used in global biogeochemical models and, for comparison, of two high-complexity models (C.CANDI and BRNS-global). The numbers of layers or nodes were taken from the respective papers and are only relevant for components whose concentration profiles are spatially resolved and not for those that are supposed to be well mixed (see Table 2). " $n$ layers" means that the number of layers is not fixed but grows as simulations proceed. For GEOCLIM reloaded, the number of layers was estimated from the given thicknesses of the topmost and the bottommost layers as well as the reported grid-point distribution function. OMEN-SED has four functional biogeochemical layers based upon redox zonation; their thicknesses adjust on the oceanic boundary conditions.

\begin{tabular}{llll}
\hline Model and reference & Resolution & Thickness & Core layers \\
\hline Archer (1991) & 10 layers & $10 \mathrm{~cm}$ & - \\
Archer (1996a) & 13 layers & $10 \mathrm{~cm}$ & - \\
HAMOCC 2s (Heinze et al., 1999) & 10 layers & $10 \mathrm{~cm}$ & 1 \\
HAMOCC 5.1 (Maier-Reimer et al., 2005) & 12 layers & $14 \mathrm{~cm}$ & 1 \\
HAMOCC 5.2 (Ilyina et al., 2013a) & 12 layers & $14 \mathrm{~cm}$ & 1 \\
MUDS (Archer et al., 2002) & 17 layers & $100 \mathrm{~cm}$ & - \\
MEDUSA (v. 1, Munhoven, 2007) & 21 nodes & $10 \mathrm{~cm}$ & $n$ \\
CESM-MEDUSA (Kurahashi-Nakamura et al., 2020) & 21 nodes & $10 \mathrm{~cm}$ & $n$ \\
SEDGEM (Ridgwell and Hargreaves, 2007) & $1+n$ layers & $5+n \mathrm{~cm}$ & $($ included) \\
DCESS-ESM (Shaffer et al., 2008) & 7 layers & $10 \mathrm{~cm}$ & $?$ \\
GEOCLIM reloaded(Arndt et al., 2011) & $\sim 100$ nodes & $100 \mathrm{~cm}$ & - \\
OMEN-SED (Hülse et al., 2018) & 4 layers & dynamic & - \\
\hline C.CANDI (Luff et al., 2000) & 1000 layers & $25 \mathrm{~cm}$ & - \\
BRNS-global (Jourabchi et al., 2005) & 251 nodes & $165 \mathrm{~cm}$ & - \\
\hline
\end{tabular}

alisation pathways of organic matter in the standard sediment model of HAMOCC: in HAMOCC 5.1 (Maier-Reimer et al., 2005) denitrification was added, and in HAMOCC 5.2 (Ilyina et al., 2013b) sulfate reduction was added. Gehlen et al. (2006) coupled a slightly extended version of the sediment model of Heinze et al. (1999) to PISCES, the biogeochemical component of NEMO, with nitrate reduction and denitrification as an additional remineralisation pathway for organic matter. The Gehlen et al. (2006) model was also later introduced as the sediment component into Bern3D (Tschumi et al., 2011).

Box models and box-diffusion models of the ocean carbon cycle have an even longer-standing history of including ocean-sediment exchange schemes. For a long time, box models, in particular, were the only types of models that could be used to carry out analyses on timescales of several thousand to tens or hundreds of thousands of years. Hoffert et al. (1981) outlined the fundamentals of a simple oceansediment exchange scheme for their box-diffusion carbon cycle model, but without actually using it in the end, so Keir and Berger (1983) appear to have been the first to couple a vertically integrated sediment model to a two-box representation of the ocean-atmosphere carbon cycle for their study of glacial-interglacial $\mathrm{CO}_{2}$ variations. The theoretical foundations of that scheme were presented in Keir (1982) (see also Munhoven, 1997, for a variant and additional details). In that scheme, the surface sediment was assumed to be well mixed, with clay and calcite as the only solid components and with $\mathrm{CO}_{3}^{2-}$ as the only modelled solute in the pore water. By furthermore adopting a calcite dissolution rate pro- portional to $f(1-\Omega)^{n}$, where $f$ is the calcite fraction in the solid phase, $\Omega$ the degree of supersaturation with respect to calcite and $n$ the dissolution rate order, the steady-state pore-water profile of $\mathrm{CO}_{3}^{2-}$ can be calculated. The total dissolution rate can then be set equal to the diffusive flux of $\mathrm{CO}_{3}^{2-}$ at the sediment-water interface (SWI), which is proportional to $\sqrt{f}\left(1-\Omega_{\mathrm{SWI}}\right)^{\frac{n+1}{2}}$. This same scheme and variants of it have afterwards been used in a large variety of box and box-diffusion models with increasingly better geographical resolution as time evolved: Sundquist (1986) with unreported $n$, CYCLOPS (Keir, 1988) with $n=4.5$, Walker and Opdyke (1995) with $n=1$, MBM (multi-box model, Munhoven and François, 1996; Munhoven, 1997) with $n=$ 4.5. Sigman et al. (1998) reconsidered the CYCLOPS model of Keir (1988) and replaced the purely $\mathrm{CO}_{3}^{2-}$-driven dissolution scheme by a meta-model based upon a multivariate polynomial expression fitted to the calcite dissolution rates obtained with the model of Martin and Sayles (1996) under various boundary conditions, also capable of taking into account the effect of pore-water $\mathrm{CO}_{2}$ derived from the respiration of organic matter on promoting calcite dissolution in the sedimentary mixed layer. Munhoven (2007) finally replaced the 304 vertically integrated sediment boxes in MBM by as many vertically resolved and fully coupled MEDUSA v1 sediment columns (see Sect. 1.2 for details). The oceansediment exchange schemes in all of the three MBM versions furthermore tracked the history of deposition of the sediment solids and could thus consistently take into account the effect of chemical erosion events. 
There are various means to alleviate the computational overburden caused by adding a vertically resolved early diagenesis model to a biogeochemical ocean model. First of all, the number of vertical layers and of chemical constituents or the complexity of the reaction network can be reduced. Most EMICs that include a vertically resolved sediment module appear to follow that pathway (see Tables 1 and 2): UVic 2.9 (Eby et al., 2009) and CLIMBER 2 (Brovkin et al., 2012) both include the oxic-only model of Archer (1996a) with 13 vertical layers; DCESS-ESM (Shaffer et al., 2008) includes a hybrid category 3-4 ocean-sediment exchange scheme considering $\mathrm{CO}_{3}^{2-}, \mathrm{O}_{2}$ and organic carbon distributions in seven layers, as well as calcite and clay contents vertically integrated. Shaffer et al. (2008) furthermore use parameterised exponential concentration profile solutions in each layer. Parameter values are then chosen on the basis of concentration and flux continuity considerations at the layer boundaries to assemble the different pieces into the final concentration profiles. Hülse et al. (2018) adopted a somewhat similar strategy for OMEN-SED, which complements the carbonate preservation scheme SEDGEM in cGENIE (the carbon-centric version of GENIE) with an organic matter preservation scheme. Instead of piecewise analytical concentration profiles as in DCESS, OMEN-SED uses piecewise analytical organic matter reaction rate profiles in the four redox layers and assembles the resulting partial concentration profiles on the basis of similar continuity conditions. For the coupling of OMEN-SED with cGENIE, the overall early diagenetic reaction network was further simplified by neglecting the impact of organic carbon respiration on carbonate dissolution. One may also reduce the number of spatially distributed sediment columns. This approach was adopted for GEOCLIM reloaded (Arndt et al., 2011). The ocean module of GEOCLIM reloaded consists of an advective-diffusive inner ocean, completed by two two-box (surface and deep) ensembles for the polar and epicontinental seas. The inner ocean is divided into several hundred $10 \mathrm{~m}$ thick layers. The ocean-sediment exchange scheme, however, consists of only three vertically resolved sediment columns attached to the polar, inner and epicontinental water columns. In each of the three sediment columns the complete cascade of organic matter oxidation pathways from aerobic respiration to $\mathrm{NO}_{3}^{-}$, $\mathrm{Mn}(\mathrm{IV}), \mathrm{Fe}(\mathrm{III})$ and $\mathrm{SO}_{4}^{2-}$ reduction to $\mathrm{CH}_{4}$ formation as well as a series of secondary redox reactions are taken into account. Even with this strongly reduced resolution of the ocean-sediment exchange scheme, the computation impact remains considerable: Arndt et al. (2011) report that $1 \mathrm{~d}$ of CPU time allowed for a $1 \mathrm{Myr}$ simulation without sediments, but only for a $100 \mathrm{kyr}$ simulation with sediments. Finally, the ocean-sediment exchange scheme and the ocean biogeochemical calculations may be carried out with different time steps (asynchronous coupling). This approach is followed in GENIE (Ridgwell, 2007; Ridgwell and Hargreaves,
2007) and MBM (Munhoven and François, 1996; Munhoven, 1997, 2007).

Sea-floor sediments are not only relevant as "processing units" for biogenic material raining down from the surface euphotic layer, during which some parts get remineralised (i.e. oxidised or dissolved) and the rest gets buried. Burial is, however, at first only temporary. Changes in the overlying boundary conditions (e.g. saturation conditions) may indeed lead to chemical erosion episodes during which the surface sedimentary mixed layer loses material faster than it is replenished by deposition from the water column above. We are currently at the onset of such an episode: as ocean acidification due to the uptake of anthropogenic $\mathrm{CO}_{2}$ progresses to the deep ocean, the resulting change in the degree of saturation with respect to carbonate minerals is expected to enhance the dissolution of carbonates in the sea-floor surface sediments at depth so strongly that the dissolution rate will exceed the rate at which carbonate material gets deposited at the sediment water interface (Archer et al., 1998). Previously buried carbonates will then return to the sedimentary mixed layer as a result of the bioturbation activity, which tends to keep the surface mixed layer at a rather stable thickness that seems to be controlled by the supply of organic matter (Boudreau, 1998). Archer (1996b) estimates that existing carbonates in surface sea-floor sediment can neutralise about $1600 \mathrm{GtC}$, which is considerably more than the $\sim 1000 \mathrm{GtC}$ that may at most be emitted while still limiting global anthropogenic temperature change to below $2^{\circ} \mathrm{C}$ (e.g. Zickfeld et al., 2016) but much less than the estimated resources of fossil fuels of 8543-13 $649 \mathrm{GtC}$ (Bruckner et al., 2014, Table 7.2).

Finally it should not be forgotten that sea-floor sediments represent our most comprehensive source of information about past climate change, and it is of course indispensable to understand how early diagenetic processes influence the sedimentary record. It would be desirable to directly compare generated model (synthetic) sedimentary records to the observed records, thus opening new possibilities in terms of data assimilation.

\subsection{MEDUSA: from version 1 to version 2}

The first version of the Model of Early Diagenesis in the Upper Sediment, ${ }^{1}$ MEDUSA - hereafter MEDUSA v1 - was described in Munhoven (2007). It is a time-dependent vertically resolved biogeochemical model of the early diagenesis processes in the sea-floor sediment. MEDUSA v1 included clay, calcite, aragonite and organic matter as solid components and $\mathrm{CO}_{2}, \mathrm{HCO}_{3}^{-}, \mathrm{CO}_{3}^{2-}$ and $\mathrm{O}_{2}$ as pore-water solutes. Besides that configuration, two others (unpublished) were developed: one which furthermore included opal and

\footnotetext{
${ }^{1}$ The final "A" did not have any particular meaning initially, although music lovers amongst early diagenetic modellers will undoubtedly have read it as "Ab minor."
} 
Table 2. Pore-water and solid-phase species in sediment models used in global biogeochemical models and, for comparison, in two typical applications of high-complexity models (C.CANDI, which has been coupled to a regional ocean model for short-term applications of a few years only, and BRNS-global, which has been mainly used for steady-state studies of individual stations). In the solids' column, "Clay" should be understood to stand for any inert, detrital or dilutant material.

\begin{tabular}{|c|c|c|}
\hline Model & Solutes & Solids \\
\hline Archer (1991) & $\mathrm{CO}_{2}, \mathrm{HCO}_{3}^{-}, \mathrm{CO}_{3}^{2-}, \mathrm{O}_{2}$ & $(\text { calcite, clay })^{\mathrm{a}}(\mathrm{OrgC})^{\mathrm{b}}$ \\
\hline Archer (1996a) & $\mathrm{CO}_{2}, \mathrm{HCO}_{3}^{-}, \mathrm{CO}_{3}^{2-}, \mathrm{B}(\mathrm{OH})_{3}, \mathrm{~B}(\mathrm{OH})_{4}^{-}, \mathrm{O}_{2}$ & $(\text { calcite, clay) })^{\mathrm{a}} \mathrm{OrgC}$ \\
\hline $\begin{array}{l}\text { HAMOCC 2s } \\
\text { (Heinze et al., 1999) }\end{array}$ & $\mathrm{TCO}_{2}$, TAlk, $\mathrm{O}_{2}, \mathrm{PO}_{4}^{3-}, \mathrm{Si}(\mathrm{OH})_{4}$ & $\begin{array}{l}\text { clay, }{ }^{12} \mathrm{C} \text { calcite, }{ }^{13} \mathrm{C} \text { calcite, }{ }^{14} \mathrm{C} \text { calcite, } \\
\text { Org }{ }^{12} \mathrm{C} \text {, Org }{ }^{13} \mathrm{C} \text {, Org }{ }^{14} \mathrm{C} \text {, opal }\end{array}$ \\
\hline $\begin{array}{l}\text { HAMOCC } 5.1 \\
\text { (Maier-Reimer et al., 2005) }\end{array}$ & $\mathrm{TCO}_{2}$, TAlk, $\mathrm{O}_{2}, \mathrm{PO}_{4}^{3-}, \mathrm{Si}(\mathrm{OH})_{4}$ & clay, calcite, OrgC, opal \\
\hline $\begin{array}{l}\text { HAMOCC } 5.2 \\
\text { (Ilyina et al., 2013a) }\end{array}$ & $\mathrm{TCO}_{2}$, TAlk, $\mathrm{O}_{2}, \mathrm{PO}_{4}^{3-}, \mathrm{Si}, \mathrm{NO}_{3}^{-}, \mathrm{Fe}, \mathrm{N}_{2}$ & clay, calcite, OrgC, opal \\
\hline $\begin{array}{l}\text { MUDS } \\
\text { (Archer et al., 2000, 2002) }\end{array}$ & $\begin{array}{l}\mathrm{CO}_{2}, \mathrm{HCO}_{3}^{-}, \mathrm{CO}_{3}^{2-}, \mathrm{O}_{2}, \mathrm{NO}_{3}^{-}, \mathrm{Si}(\mathrm{OH})_{4}, \mathrm{Mn}^{2+}, \\
\mathrm{Fe}^{2+}, \mathrm{NH}_{4}^{+}\end{array}$ & $\begin{array}{l}\text { clay, calcite, } \mathrm{OrgC}_{\text {fast }}, \mathrm{OrgC}_{\text {slow }} \\
\text { opal, } \mathrm{MnO}_{2}, \mathrm{FeOOH}\end{array}$ \\
\hline $\begin{array}{l}\text { MEDUSA (v. 1, } \\
\text { Munhoven, 2007) }\end{array}$ & $\mathrm{CO}_{2}, \mathrm{HCO}_{3}^{-}, \mathrm{CO}_{3}^{2-}, \mathrm{O}_{2}$ & clay, calcite, aragonite, $\mathrm{OrgC}$ \\
\hline $\begin{array}{l}\text { CESM-MEDUSA } \\
\text { (Kurahashi-Nakamura et al., 2020) }\end{array}$ & $\begin{array}{l}\mathrm{CO}_{2}, \mathrm{HCO}_{3}^{-}, \mathrm{CO}_{3}^{2-}, \mathrm{O}_{2}, \mathrm{H}_{4} \mathrm{SiO}_{4}, \mathrm{NO}_{3}^{-}, \\
\mathrm{DI}^{13} \mathrm{C}, \mathrm{DI}^{14} \mathrm{C}\end{array}$ & $\begin{array}{l}\text { clay, calcite, }{ }^{13} \mathrm{C} \text { calcite, }{ }^{14} \mathrm{C} \text { calcite, } \text { OrgC, } \\
\text { Org }{ }^{13} \mathrm{C} \text {, Org }{ }^{14} \mathrm{C} \text {, opal }\end{array}$ \\
\hline $\begin{array}{l}\text { SEDGEM (Ridgwell and } \\
\text { Hargreaves, 2007) }\end{array}$ & - & clay, calcite, ${ }^{13} \mathrm{C}$ calcite, ${ }^{14} \mathrm{C}$ calcite, \\
\hline SEDGEM (Ridgwell, 2007) & - & clay, calcite, ${ }^{13} \mathrm{C}$ calcite, ${ }^{14} \mathrm{C}$ calcite, opal \\
\hline $\begin{array}{l}\text { DCESS-ESM } \\
\text { (Shaffer et al., 2008) }\end{array}$ & $\mathrm{CO}_{3}^{2-}, \mathrm{O}_{2}$ & $(\text { calcite, clay) })^{\mathrm{a}} \mathrm{OrgC}$ \\
\hline $\begin{array}{l}\text { GEOCLIM reloaded } \\
\text { (Arndt et al., 2011) }^{\mathrm{c}}\end{array}$ & $\begin{array}{l}\mathrm{TCO}_{2}, \mathrm{TAlk}, \mathrm{THS}, \mathrm{TB}, \mathrm{O}_{2}, \mathrm{PO}_{4}^{3-}, \mathrm{NO}_{3}^{-}, \mathrm{NH}_{4}^{+}, \\
\mathrm{H}_{2} \mathrm{~S}, \mathrm{SO}_{4}^{2-}, \mathrm{CH}_{4}\end{array}$ & POC, PIC \\
\hline $\begin{array}{l}\text { OMEN-SED } \\
\text { (Hülse et al., 2018) }^{\mathrm{d}}\end{array}$ & $\mathrm{TCO}_{2}$, TAlk, $\mathrm{O}_{2}, \mathrm{NO}_{3}^{-}, \mathrm{NH}_{4}^{+}, \mathrm{SO}_{4}^{2-}, \mathrm{PO}_{4}^{3-}$ & $\mathrm{POC}_{1}, \mathrm{POC}_{2}$ and optionally $\mathrm{POC}_{3}$ \\
\hline $\begin{array}{l}\text { C.CANDI (Luff et al., 2000, } \\
\text { Luff and Moll, 2004) }\end{array}$ & $\begin{array}{l}\mathrm{O}_{2}, \mathrm{NO}_{3}^{-}, \mathrm{Mn}^{2+}, \mathrm{Fe}^{2+}, \mathrm{SO}_{4}^{2-}, \mathrm{CH}_{4}, \mathrm{TPO}_{4}, \mathrm{TNH}_{4}, \\
\mathrm{H}_{2} \mathrm{~S}, \mathrm{HS}^{-}, \mathrm{CO}_{2}, \mathrm{HCO}_{3}^{-}, \mathrm{CO}_{3}^{2-}\end{array}$ & $\mathrm{MnO}_{2}, \mathrm{Fe}(\mathrm{OH})_{3}, \mathrm{POC}_{\# 0}, \mathrm{POC}_{\# 1}, \mathrm{POC}_{\# 2}, \mathrm{FeS}$ \\
\hline $\begin{array}{l}\text { BRNS-global } \\
\text { (Jourabchi et al., 2005) }^{\mathrm{c}}\end{array}$ & $\begin{array}{l}\mathrm{CO}_{2}, \mathrm{HCO}_{3}^{-}, \mathrm{CO}_{3}^{2-}, \mathrm{O}_{2}, \mathrm{NO}_{3}^{-}, \mathrm{Mn}^{2+}, \mathrm{Fe}^{2+}, \mathrm{NH}_{4}^{+}, \\
\mathrm{Ca}^{2+}, \mathrm{SO}_{4}^{2-}, \mathrm{H}_{2} \mathrm{~S}, \mathrm{HS}^{-}, \mathrm{CH}_{4}, \mathrm{~B}(\mathrm{OH})_{3}, \mathrm{~B}(\mathrm{OH})_{4}^{-}\end{array}$ & OrgC, calcite, $\mathrm{MnO}_{2}, \mathrm{Fe}(\mathrm{OH})_{3}, \mathrm{FeS}, \mathrm{FeCO}_{3}, \mathrm{MnCO}_{3}$ \\
\hline
\end{tabular}

a Supposed to be well mixed, i.e. only total contents of the bioturbated layer traced. ${ }^{\mathrm{b}}$ OrgC concentration profile prescribed following Emerson (1985). ${ }^{\mathrm{c}}$ Solids' advection rate profile prescribed and therefore no clay or other inert solid component considered. ${ }^{\mathrm{d}}$ Solids' burial rate prescribed and therefore no clay or other inert solid component considered.

dissolved silica and one which also included the ${ }^{13} \mathrm{C}$ isotopic signatures of all carbon-bearing components.

Right from the beginning, MEDUSA was developed as a sediment module for the diverse ocean biogeochemical models used in our research group, ranging from box to threedimensional models, the latter with diverse grid configurations and also various sets of chemical tracers. Furthermore, our research interests required a model that could be used in studies dealing with timescales ranging from tens of years to hundreds of thousands of years. Accordingly, the model requirements were laid out as follows: (1) the model code should be customisable to accommodate different chemical compositions; (2) the model should offer the possibility to be coupled to strongly different host model grid layouts; (3) it should be possible to run the model with variable time steps; and (4) the model must be able to cope with chemical erosion, i.e. be able to recover previously buried material from deeper layers and to return it to the chemically reactive mixed layer.

The customisation options offered by MEDUSA v1 had to be selected with pre-processor directives in the code. Extending the capabilities of the model on the basis of that mechanism had become more and more cumbersome and difficult to manage with time. The code was therefore revised in depth and only the parts related to the transport terms in the equations and the equation system solver - the framework system 
- were kept. The rest of the code was from then on purposebuilt for each application with a code configuration and generation tool that would produce and assemble the parts related to the components, processes (reactions) and chemical equilibria required. A code generator was developed to read in the required information, such as chemical and physical properties of components, chemical reactions describing diagenetic processes, and chemical equilibria from a series of description files. These description files use a format based upon the eXtensible Markup Language (XML) syntax (W3C, 2008). Organising the information in an XML tree offers attractive flexibility: such a tree can be easily extended for later developments and it is possible to access any particular information wherever it is located in a file. XML thus offers a high degree of compatibility between subsequent versions of the configurator, which can always extract the relevant information as long as the required mark-up tags remain present. Above all, XML files remain mostly human-readable, and the possibility to insert comments makes it possible to ensure the traceability of the stored information.

As the complete tool was meant to require only a Fortran compiler to be built, a simple library, called $\mu$ XML, for reading and processing basic ASCII-encoded XML files in Fortran 95 was developed as a prerequisite.

\section{Model description}

\subsection{Vertical partitioning of the sediment column}

The complete sediment column is subdivided into three (or four) different vertically stacked parts (called realms), as illustrated in Fig. 1: (1) REACLAY, the topmost part extending downwards from the sediment top at the sediment-water interface and where the chemical reactions are taken into consideration; and (2) TRANLAY, the transition layer of changing thickness just underneath, acting as a temporary storage to connect REACLAY to the underlying (3) CORELAY, a stack of sedimentary layers representing the deep sediment, i.e. the sediment core. Additionally, an optional diffusive boundary layer (DBL - not to scale in Fig. 1) acting as a diffusive barrier to the sediment-water exchange of solutes can be included on top of the REACLAY realm. REACLAY includes the bioturbated sedimentary mixed layer, where most of the reactions relevant for early diagenesis take place (organic matter remineralisation, carbonate dissolution, etc.).

\subsubsection{Equations in the DBL and REACLAY realms}

In the REACLAY realm, MEDUSA solves the standard timedependent diagenetic equation (e.g. Berner, 1980; Boudreau, 1997), which can be written for each sediment component $i$ (solid or solute) in generic form as

$$
\frac{\partial \hat{C}_{i}}{\partial t}+\frac{\partial \hat{J}_{i}}{\partial z}-\hat{S}_{i}=0
$$

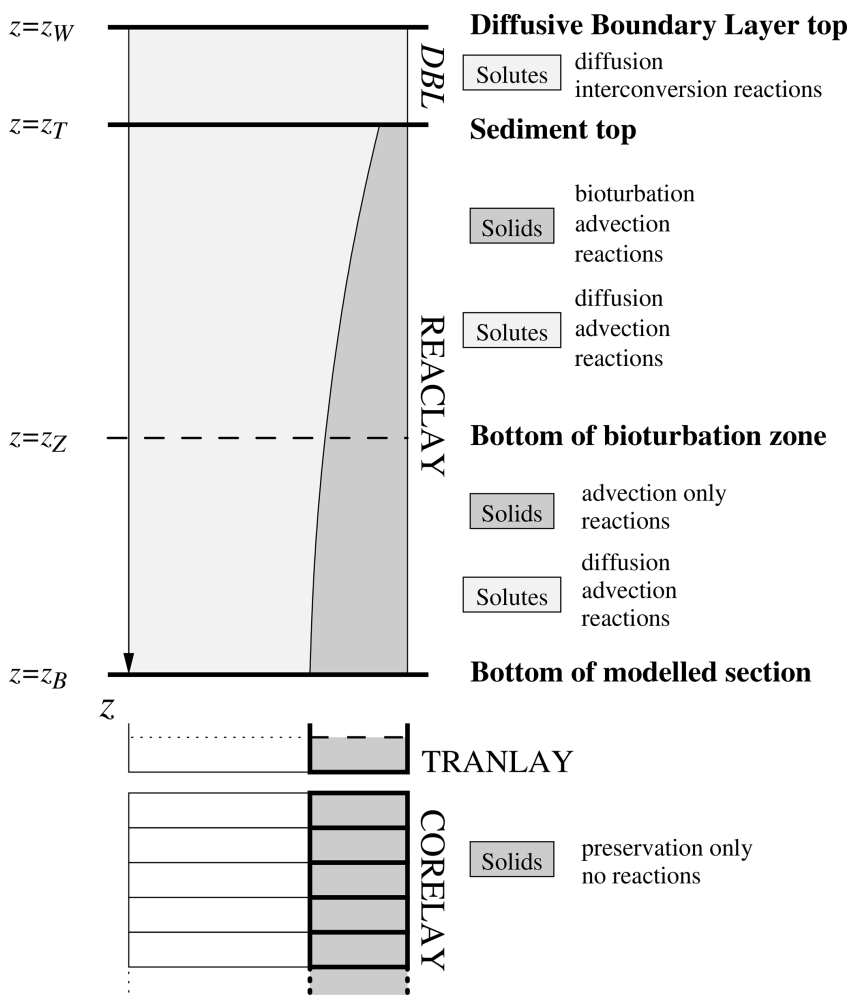

Figure 1. Partitioning of the sediment column in MEDUSA: an optional diffusive boundary layer (DBL) on top of the main part of the model sediment where diagenetic reactions and advective-diffusive transport take place (REACLAY), the transition layer (TRANLAY) and the core represented by the stack of layers (CORELAY). The bottom of the bioturbation zone may coincide with the bottom of REACLAY. If the optional DBL is omitted, $z \mathrm{~W}=z_{\mathrm{T}}$. See text for further details.

In this equation, $t$ is time and $z$ depth below the SWI (positive downwards - see Fig. 1). $\hat{C}_{i}$ denotes the concentration of $i$ in moles for solutes and in kilograms for solids per unit volume of total sediment (solids plus pore water). $\hat{J}_{i}$ is the local transport (advection and diffusion), per unit surface area of total sediment. $\hat{S}_{i}=\hat{R}_{i}+\hat{r}_{i}+\hat{Q}_{i}$ represents the net sourceminus-sink balance for constituent $i$ per unit volume of total sediment, where $\hat{R}_{i}$ is the net reaction rate equal to the difference between production and destruction (or decay) rates, $\hat{r}_{i}$ is the net fast reaction rate that is going to be filtered out of the equations by equilibrium considerations, and $\hat{Q}_{i}$ is the non-local transport (considered only for solutes). The total sediment concentrations $\hat{C}_{i}$ are related to the more directly accessible phase-specific concentrations $C_{i}^{\mathrm{s}}$ (for solids) and $C_{i}^{\mathrm{f}}$ (for solutes) by $\hat{C}_{i}=\varphi^{\mathrm{s}} C_{i}^{\mathrm{s}}$ and $\hat{C}_{i}=\varphi^{\mathrm{f}} C_{i}^{\mathrm{f}}$, respectively. $\varphi^{\mathrm{s}}$ and $\varphi^{\mathrm{f}}$ denote the volume fractions of bulk solids and of pore water in the total sediment, linked to porosity $\varphi$ by $\varphi^{\mathrm{s}}(z)=1-\varphi(z)$ and $\varphi^{\mathrm{f}}(z)=\varphi(z)$. The porosity profile $\varphi(z)$ is prescribed but may be different for each column in multicolumn set-ups. 
In the DBL (if any), only equations for solutes are considered and porosity is set to 1 . Solids are supposed to rain through the DBL and directly enter REACLAY at its top surface.

\section{Chemical reactions and equilibria}

The set of chemical reactions and equilibria to consider is completely dependent upon the given application, i.e. on the chemical composition of the sediments required, the diagenetic processes to consider (e.g. organic matter remineralisation, possibly following several pathways, carbonate dissolution) and the equilibria between components of solute systems (e.g. carbonate, phosphate, borate systems) to take into account. MEDUSA does not include a standard composition and reaction-equilibrium network but must be configured to fit the complexity requirements of a given application: including one or more classes of organic matter (solid or dissolved), one or more types of carbonates and one or more organic matter degradation processes.

The chemical interconversion reactions represented by the $\hat{r}_{i}$ terms in the source-minus-sink term $\hat{S}_{i}$ are orders of magnitude faster than all other reactions. They are supposed to evolve in quasi-equilibrium. The $\hat{r}_{i}$ terms are therefore eliminated from the partial differential equation system by considering appropriate linear combinations of selected equations and by including the thermodynamic equilibrium equations in the system of equations. The partial differential equation system is thus converted into a differential algebraic equation (DAE) system. The subroutines required to evaluate the source and sink terms related to chemical reactions and to convert the complete system to a DAE system are generated by the companion MEDUSA COnfiguration and COde GENeration tool (MEDUSACOCOGEN) described in Sect. 2.4.

\section{Transport}

Solids are transported by advection throughout the sediment column and subject to bioturbation in the surface mixed layer. Bioturbation is represented as a diffusive process. Both interphase and intraphase biodiffusion variants (Boudreau, 1986) are taken into account and can be combined. With interphase biodiffusion the bulk sediment gets mixed by infaunal activity, solids and pore water alike, and porosity gradients are thus affected as well; with intraphase biodiffusion only the solid-phase constituents get mixed:

$\hat{J}_{i}=-D_{i}^{\text {inter }} \frac{\partial \varphi^{\mathrm{s}} C_{i}^{\mathrm{s}}}{\partial z}-\varphi^{\mathrm{s}} D_{i}^{\text {intra }} \frac{\partial C_{i}^{\mathrm{s}}}{\partial z}+\varphi^{\mathrm{s}} w C_{i}^{\mathrm{s}}$.

Here, $D_{i}^{\text {inter }}$ and $D_{i}^{\text {intra }}$ are respectively the interphase and intraphase biodiffusion coefficients of the solid $i ; w$ is the solids' advection rate. We suppose that the biodiffusion coefficients within a given sediment column are the same for all solids: $D_{i}^{\text {inter }}(z) \equiv D^{\text {inter }}(z)$ and $D_{i}^{\text {intra }}(z) \equiv D^{\text {intra }}(z)$. For convenience, we define $D^{\mathrm{bt}}(z)=D^{\text {inter }}(z)+D^{\text {intra }}(z)$ and
$D^{\text {inter }}(z)=\beta(z) D^{\mathrm{bt}}(z)$, where $\beta(z)$ sets the interphase fraction of the biodiffusion process $(\beta=0$ for the intraphase and $\beta=1$ for the interphase endmembers). After application of the chain rule to the derivative in the interphase diffusion term, $\hat{J}_{i}$ becomes

$\hat{J}_{i}=-\varphi^{\mathrm{s}} D^{\mathrm{bt}} \frac{\partial C_{i}^{\mathrm{s}}}{\partial z}+\left(\varphi^{\mathrm{s}} w-\beta D^{\mathrm{bt}} \frac{\partial \varphi^{\mathrm{s}}}{\partial z}\right) C_{i}^{\mathrm{s}}$.

The advection rate profile $w(z)$ is derived from the depthintegrated solid-phase volume conservation equation:

$$
\begin{aligned}
& \varphi^{\mathrm{s}}(z) w(z)-\beta(z) D^{\mathrm{bt}}(z) \frac{\partial \varphi^{\mathrm{s}}}{\partial z} \\
& =\sum_{i \in \mathcal{I}^{\mathrm{s}}} \vartheta_{i} \hat{I}_{i}^{\mathrm{top}}+\int_{z_{T}}^{z} \sum_{i \in \mathcal{I}^{\mathrm{s}}} \vartheta_{i} \hat{R}_{i}\left(z^{\prime}\right) \mathrm{d} z^{\prime},
\end{aligned}
$$

where $\mathcal{I}^{\mathrm{s}}$ denotes the inventory of solid components considered in the model configuration, $\vartheta_{i}$ the partial specific volume of solid $i$ and $\hat{I}_{i}^{\text {top }}$ its deposition rate per unit surface of total sediment per unit time entering the surface sediment through the sediment-water interface at the top. We suppose that the densities $\rho_{i}$ of individual solid components are constant and independent of each other. In this case, $\vartheta_{i}=1 / \rho_{i}$ and the $\vartheta_{i}$ terms are also constant and commute with the partial derivatives. Equation (3) is obtained by considering the sum of all the solids' evolution equations (Eq. 1) weighted by the respective partial specific volumes, together with the static volume conservation equation:

$\sum_{i \in \mathcal{I}^{\mathrm{s}}} \vartheta_{i} C_{i}^{\mathrm{s}}=1$

In the current version of MEDUSA porosity profiles are assumed to be at steady state, although this might change in the future. For non-steady-state porosity profiles, the right-hand side of Eq. (3) has to be reduced by $\int_{z T}^{z} \frac{\partial \varphi^{\mathrm{s}}}{\partial t} \mathrm{~d} z^{\prime}$.

Although the density of each solid constituent is constant, the average density of the solid phase may vary in both space and time as chemical reactions proceed, modify the sediment composition and thereby influence the advection rate profiles. To ensure compatibility with other early diagenesis models which assume that the solid phase has a constant density (both in space and time) and that the effect of chemical reactions on the sediment mass (and volume) is negligible, all the solid components but the mandatory inert one can optionally be declared volumeless.

Solutes are transported by molecular and ionic diffusion in pore waters, interphase bioturbation, pore-water advection and bioirrigation. The complete expression for the local transport term of a pore-water solute $i$ would thus be written

$\hat{J}_{i}=-\varphi^{\mathrm{f}} \frac{D_{i}^{\mathrm{sw}}}{\theta^{2}} \frac{\partial C_{i}^{\mathrm{f}}}{\partial z}-D_{i}^{\mathrm{inter}} \frac{\partial \varphi^{\mathrm{f}} C_{i}^{\mathrm{f}}}{\partial z}+\varphi^{\mathrm{f}} u C_{i}^{\mathrm{f}}$,

where $D_{i}^{\mathrm{sw}}$ is the free diffusion coefficient of the solute $i$ in seawater, $\theta^{2}$ is tortuosity and $u$ is the pore-water advection 
rate. Applying the chain rule to the second term on the righthand side and collecting similar terms, we get

$$
\hat{J}_{i}=-\varphi^{\mathrm{f}}\left(\frac{D_{i}^{\mathrm{sw}}}{\theta^{2}}+\beta D^{\mathrm{bt}}\right) \frac{\partial C_{i}^{\mathrm{f}}}{\partial z}+\left(\varphi^{\mathrm{f}} u-\beta D^{\mathrm{bt}} \frac{\partial \varphi^{\mathrm{f}}}{\partial z}\right) C_{i}^{\mathrm{f}} .
$$

In the absence of impressed flow, transport by pore-water advection is negligible compared to diffusion; biodiffusion coefficients are furthermore an order of magnitude lower than molecular and ionic diffusion coefficients. The expression for the local transport term of a pore-water solute $i$ adopted in MEDUSA then simplifies to

$$
\hat{J}_{i}=-\varphi^{\mathrm{f}} \frac{D_{i}^{\mathrm{sw}}}{\theta^{2}} \frac{\partial C_{i}^{\mathrm{f}}}{\partial z} .
$$

Tortuosity is parameterised as a function of porosity, and the diffusion coefficients of individual solutes are calculated as a function of temperature, corrected for pressure and salinity by using the dynamic viscosity. ${ }^{2}$

It should be noted that in the current version of MEDUSA, neglecting advection and the effect of interphase biodiffusion on solutes contributes to ensuring a more precise mass balance. Pore-water advection could still be considered for steady-state applications, where $u_{\text {tot }}=u-\frac{\beta D^{\mathrm{bt}}}{\varphi^{\mathrm{ft}}} \frac{\partial \varphi^{\mathrm{f}}}{\partial z}$ would always be oriented downwards. However, in transient simulation experiments, where $u$ may temporarily be oriented upwards (unburial, chemical erosion), pore waters would flow into the REACLAY realm, requiring knowledge of solute concentrations below the modelled domain. The latter, however, are not currently tracked.

Bioirrigation provides a non-local transport mode for solutes. In MEDUSA, the source-sink approach (Boudreau, 1984 ) is used to quantify the effect of bioirrigation:

$$
\hat{Q}_{i}=\alpha \varphi^{\mathrm{f}}\left(C_{i}^{\mathrm{oc}}-C_{i}^{\mathrm{f}}\right) .
$$

Here, $\alpha$ is the bioirrigation "constant", which may be depthdependent, and $C_{i}^{\mathrm{oc}}$ the concentration of solute $i$ in the irrigation channels, set equal to the solute's concentration in the seawater overlying the sediment.

\section{Boundary conditions}

The differential equation systems describing the evolutions of the compositions of the DBL and REACLAY realms have to be completed by boundary conditions connecting them to the overlying seawater, the underlying TRANLAY and between each other. Solute concentrations at the top are derived from those in the overlying ocean water $\left(C_{i}^{\mathrm{f}}\left(z_{\mathrm{W}}, t\right)=C_{i}^{\mathrm{oc}}(t)\right.$ - a Dirichlet boundary condition), prescribed at the top of the DBL if the model set-up includes one and directly at the SWI

\footnotetext{
${ }^{2}$ Details about these calculations can be found in Sect. 2.4.2 in the technical report "Early Diagenesis in Sediments: A onedimensional model formulation" in the Supplement.
}

if not. If a DBL is included in the model set-up solute concentrations at the SWI (i.e. at the interface between the DBL and the REACLAY realm) are derived by assuming concentration and flux continuity across that interface (Cauchy boundary condition). Solids reaching the sea floor are assumed to "rain through" the DBL (if any) and enter the sediment only at the SWI where flux continuity is used as a boundary condition (leading to a Robin boundary condition).

At the bottom of the REACLAY realm, flux continuity is adopted for both solutes and solids. For solutes, this requires the concentration gradient to reduce to zero (Neumann boundary condition) since $u(z) \equiv 0$ is adopted here. For solids, a variety of effective boundary conditions arise and the types may change in time - depending on whether biodiffusion has vanished there or not and whether the sediment is burying $\left(w_{\mathrm{B}}^{+}>0\right.$, where $w_{\mathrm{B}}^{+}$denotes the advection rate on the outer side of REACLAY's bottom interface) or eroding $\left(w_{\mathrm{B}}^{+}<0\right)$ solid material at the bottom of REACLAY.

\subsubsection{TRANLAY and CORELAY}

TRANLAY is a transition layer that collects the solids leaving REACLAY through the bottom (see Fig. 1). As soon as its thickness exceeds a given threshold value (by default $1 \mathrm{~cm}$ ) at the end of a time step, one or more new sediment core layers are formed and subtracted from TRANLAY to be transferred to CORELAY, which is managed as a last-in-first-out stack of sediment layers.

In general, material is only preserved in TRANLAY and CORELAY; it is assumed that no chemical reactions take place there. However, one exception to this rule has to be made: reactions that are part of a radioactive decay chain are still taken into account in these two realms to avoid physically unrealistic results. Radioactive material that would have left REACLAY and be returned there later during a chemical erosion event would contribute to creating unrealistically young concentrations in REACLAY if radioactive decay were temporarily suspended for a more or less extended time.

\subsection{Numerical solution of the equation system}

The complete solution of one sediment column requires the joint solution of three numerical problems: (1) a DAE system in the REACLAY realm or the combined REACLAY-DBL realms if a DBL is included; (2) a system of ordinary differential equations in the TRANLAY realm; and (3) a stack management problem in CORELAY. The three problems are interdependent. If the sediment column is accumulating, the burial flux, i.e. the solids' advection flux across the bottom of REACLAY, feeds TRANLAY and in addition new layers for CORELAY are separated from TRANLAY; if the sediment column is eroding, REACLAY is replenished by TRANLAY through its bottom and TRANLAY is replenished by the topmost layers from CORELAY if necessary. 


\subsubsection{REACLAY (and DBL)}

The DAE system is solved by using an implicit Euler method for the time dimension and a finite-volume method for the spatial dimension. For this purpose, the REACLAY and the DBL realms are partitioned into cells (finite volumes) using a so-called vertex-centred grid. Each one of these two realms is overlaid by an irregularly spaced grid of points, called nodes: each node is representative of a cell. The cell boundaries, called vertices, are located midway between adjacent nodes. The concentrations of the considered solute and solid components are evaluated at the nodes, and the fluxes between cells are evaluated at the vertices. The actual grid-point distribution is obtained by a continuously differentiable mapping of a regular grid in order to make sure that the discrete representation of the equation system is consistent and has the same discretisation order that it would have on a regular grid (Hundsdorfer and Verwer, 2003).

The bottom point of the grid that covers REACLAY is always a node. The nature of the topmost point depends on whether a DBL is included or not: if no DBL is included, the topmost interface of REACLAY - the sediment-water interface, SWI - is located at a grid node; if a DBL is included, the interface at the top of REACLAY is mapped onto a grid vertex, defined by a virtual node located above the top of REACLAY and the topmost interior node of REACLAY. Similarly, the bottom of the DBL is located at a vertex of the DBL grid, defined by a virtual node located below the bottom of the DBL and the lowest node inside the DBL (which is most often the top of the DBL). Detailed information about the grid generation can be found in the "MEDUSA Technical Reference" in the Supplement.

In multi-column set-ups - this would be the most common usage for coupling to biogeochemical cycle models - every sediment column in MEDUSA must have the same number of grid points, but the spacing and extent of each of these may be different.

\section{Discrete equations}

The discrete version of the evolution equation for a component $i$ in a cell $j$ represented by the node situated at $z_{j}$ is written as

$$
\frac{\left(\hat{C}_{i}\right)_{j}^{n}-\left(\hat{C}_{i}\right)_{j}^{n-1}}{\Delta t_{n}}+\frac{\left(\hat{J}_{i}\right)_{j+\frac{1}{2}}^{n}-\left(\hat{J}_{i}\right)_{j-\frac{1}{2}}^{n}}{h_{j}}-\left(\hat{S}_{i}\right)_{j}^{n}=0,
$$

where $\Delta t=t_{n}-t_{n-1}$ is the implicit time step and $h_{j}$ is the distance between the vertices $z_{j-\frac{1}{2}}=\frac{1}{2}\left(z_{j}+z_{j-1}\right)$ and $z_{j+\frac{1}{2}}=\frac{1}{2}\left(z_{j+1}+z_{j}\right)$ that delimit the cell $j$. Equation (6) is slightly modified at the bottommost node where it relates to a half-cell only, and one may choose to formally express the mass-balance equations for that half-cell at the representative node (which is actually the bottom node of the grid) or at some intermediate point between that node and the delim- iting vertex. In the absence of a DBL, a similar procedure is adopted at the topmost node.

The numerical schemes adopted in MEDUSA have been selected with the physical meaningfulness of the results in mind. Accordingly, positiveness of the calculated concentration evolutions was deemed indispensable. The discretisation of the advective part of the local transport term in the equations thus requires an upwinding approach. One may choose between a first-order full upwind and a secondorder exponential fitting scheme, known elsewhere as the Allen-Southwell-Il'in or the Scharfetter-Gummel scheme (Hundsdorfer and Verwer, 2003). It is closely related to the scheme of Fiadeiro and Veronis (1977): on regularly spaced grids both schemes lead to identical discrete forms of the equations. The exponential fitting scheme is, however, better suited for the flux-conservative finite-volume approach on irregularly spaced grids adopted in MEDUSA as it allows for exact mass conservation. Unlike steady-state models, wherein the solids' advection rate is always oriented downwards relative to the sediment-water interface, MEDUSA has to be able to cope with solids' advection rates that may have any orientation and that may even change their orientation with time. Both upwinding schemes automatically handle this complication.

At each node (or cell) $j$, the unknowns are the solute concentrations $\left(C_{i}^{\mathrm{f}}\right)_{j}^{n}$, the solid concentrations $\left(C_{i}^{\mathrm{s}}\right)_{j}^{n}$ and the solids' advection rate at the bottom of the cell, $w_{j+\frac{1}{2}}^{n}$. The advection rate at the top of the cell $j$ is equal to that at the bottom of the cell above $(j-1)$; the advection rate at the SWI is derived directly from the solids' deposition rate, i.e. from the top boundary conditions. The $w_{j+\frac{1}{2}}^{n}$ at each node is derived from the discrete form of Eq. (3), i.e.

$$
\begin{aligned}
& \varphi_{j+\frac{1}{2}}^{\mathrm{s}} w_{j+\frac{1}{2}}^{n}-\left.\beta_{j+\frac{1}{2}} D_{j+\frac{1}{2}}^{\mathrm{bt}} \frac{\partial \varphi^{\mathrm{s}}}{\partial z}\right|_{j+\frac{1}{2}} \\
& =\sum_{i \in \mathcal{I}^{\mathrm{s}}} \vartheta_{i}\left(\hat{I}_{i}^{\mathrm{top}}\right)^{n}+\sum_{k=T}^{j} h_{k} \sum_{i \in \mathcal{I}^{\mathrm{s}}} \vartheta_{i}\left(\hat{R}_{i}\right)_{j}^{n},
\end{aligned}
$$

which furthermore depends on the static volume conservation equation (also at each node):

$\sum_{i \in \mathcal{I}^{\mathrm{s}}} \vartheta_{i}\left(C_{i}^{\mathrm{s}}\right)_{j}^{n}=1$.

In Eq. (7), $T$ denotes the top node and/or cell and the indices $j+\frac{1}{2}$ to $\varphi^{\mathrm{s}}, \beta$ and $D^{\mathrm{bt}}$ indicate that these factors are approximations of their respective counterparts at $z_{j+\frac{1}{2}}$.

The complete system of equations is thus overdetermined: at each node, there is one more equation than there are unknowns. However, the equations are not independent of each other. At each node, Eq. (7) is a linear combination of the solids' evolution in Eq. (6) at that node and all the Eq. (7) instances in all the cells on top of cell $j$, furthermore taking Eq. (8) in each of these cells into account. One of the equations is thus redundant at each node. Equation (7) is kept at 
each node as it is most convenient to calculate the $w_{j+\frac{1}{2}}^{n}$, and static volume conservation is furthermore enforced. Accordingly, one of the solids' evolution equations may be removed at each node to resolve the overdetermination: it is most convenient to drop that for the mandatory inert solid.

\section{Solution strategy}

The discretisation of the DAE system outlined above leads to a coupled system of equations that is generally non-linear due to the expressions for the reaction rate terms $\left(\hat{R}_{i}\right)_{j}^{n}$ and needs to be solved iteratively. A full Newton-Raphson approach is unfortunately impractical: due to the Eq. (7) instances in each cell the Jacobian of the complete system is a lower block-Hessenberg matrix, which makes the linear system to solve at each iteration computationally expensive. The complete equation system is therefore partitioned into two subsets: the first one with all the Eq. (7) instances and the second one with all the remaining equations. Each iteration then proceeds in two stages. First, a fixed-point rule is used to update the advection rate profile (unknowns $w_{j+\frac{1}{2}}^{n}$ ) with the first equation subset. The required $D^{\text {bt }}, \beta$ and $\alpha$ coefficients and the reaction rate terms are evaluated by using the most recent available concentration profiles (or the initial state). In a second stage concentration profiles (unknowns $\left(C_{i}^{\mathrm{f}}\right)_{j}^{n}$ and $\left(C_{i}^{\mathrm{s}}\right)_{j}^{n}$ ) are then updated by applying a damped Newton scheme (Engeln-Müllges and Uhlig, 1996) for the second subset of equations using the advection rates calculated at the first stage and considered constants for this second stage. The algorithm uses the analytical Jacobian, which is now blocktridiagonal and the resulting linear system can be solved by a block version of the Thomas algorithm. The next iteration then starts again at the first stage, updating the advection rate profile with the fixed-point rule by using the previously updated concentration profiles and then the damped NewtonRaphson correction.

Iterations are stopped on the basis of a two-level criterion, completed by a maximum number of iterations not to exceed (120 by default). It is first required that the Euclidian norm of the scaled residuals of the second subset of equations is lower than $\sqrt{n_{C}} \times 10^{-6}$, where $n_{C}$ is the number of equations in the second subset, i.e. the total number of concentration unknowns. Once this first level is reached, we proceed to a root refinement: as long as the maximum number is not exceeded, iterations are continued until the maximum norm of the difference between consecutive scaled concentration iterates falls below $10^{-9}$. In general, the second level requires only a few extra iterations and may further reduce the equation residuals by several orders of magnitude. Iterations are deemed to have converged once the first-level condition is fulfilled before the maximum number of iterations is exceeded; furthermore, reaching the second level is considered a non-mandatory extra. The equation system is not explicitly scaled as the linear system solver performs automatic internal scaling (Engeln-Müllges and Uhlig, 1996). The characteristic scales of the components' concentrations, if provided, are nevertheless taken into account in the convergence criterion and to calculate the equation scales, which are respectively based upon the diffusion timescale of the component whose evolution they describe. For details about the scaling, please refer to the "MEDUSA Technical Reference" in the Supplement.

For the initialisation of the iterative scheme, a sequence of approaches has been implemented: (1) the state of the previous time step is used; (2) selected solute profiles are initially set homogeneously equal to the boundary values; (3) a continuation method is used whereby the partial specific volumes of all non-inert solids are gradually increased from zero to their actual values; (4) a continuation method is used whereby the top solid fluxes are gradually increased from zero to their actual given values; (5) a continuation method is used whereby reaction rates are gradually increased from zero to their standard values; (6) a continuation method is only used for steady-state calculations wherein gradually longer time steps are used; and (7) a continuation method is only used for columns subject to strong chemical erosion, whereby the amount of eroded material to return to REACLAY is gradually increased to the calculated value. These are adopted in turn until one of them leads to a sequence of iterations that fulfils the convergence criterion.

The numerical solution procedure follows an "all-at-once" strategy. Due to the general-purpose approach of the model, all chemical reactions are treated equally. It would require artificial-intelligence-based algorithms to make out efficient processing sequences for arbitrary reaction networks. With fixed compositions and reaction networks, expert knowledge allows the design of such sequential processing chains, as implemented, for example, in MUDS (Archer et al., 2002). It is, however, possible to use the code generation facilities of MEDUSA and then to modify the equation solver so that it uses a solution scheme similar to the initialisation strategy (5) whereby the reaction rate parameters are not changed homogeneously and continuously, but selectively. Such a modified equation solver would of course only be applicable for that given model configuration.

\subsubsection{TRANLAY and CORELAY}

Once the calculations for one time step in the REACLAY realm have been completed, it is checked whether the sediment column is accumulating $\left(w_{\mathrm{B}}^{+}>0\right)$ or eroding $\left(w_{\mathrm{B}}^{+}<0\right)$. If it is accumulating, the mass flux that leaves REACLAY at its bottom is added to TRANLAY; if it is eroding, then it is furthermore checked whether TRANLAY holds enough material to provide for the calculated influx into REACLAY across its bottom. If it does not, the solid contents of the most recently created layer in CORELAY are returned to TRANLAY, and the complete time step is recalculated from the be- 
ginning. This is then repeated until TRANLAY could provide enough material over the whole time step.

At this stage, the concentration and solids' advection rate profiles in REACLAY and the DBL can be accepted for the end of the time step. Finally, the thickness of TRANLAY is checked: if it is more than $10 \%$ thicker than one CORELAY layer ( $1 \mathrm{~cm}$ by default), material for as many CORELAY layers as possible is subtracted and added on top of the current CORELAY stack.

\subsection{Code organisation}

The MEDUSA common framework includes the subroutines to assemble the equation system and its Jacobian, as well as to solve the equation system, with modules to make fundamental data available (physical constants, unit conversion parameters, etc.) and modules to hold the forcing data and the intermediate results. It also provides the core management system for multiple sediment columns, which can be processed in a sequential or a parallel fashion. For parallel processing, Message Passing Interface (MPI) calls are included and can be activated by a pre-processor switch. Three different coupling application programming interfaces (APIs) are provided: $1 \mathrm{D}, 2 \mathrm{D}$ and $2 \mathrm{D} \times 2 \mathrm{D}$, respectively, for a sequential linear distribution of the sediment columns, a two-dimensional ordering (typically longitude-latitude) and a hierarchically ordered two-dimensional array of twodimensional arrays of sediment columns.

In multi-column set-ups the chemical composition (solids and pore-water solutes) must be the same in all the columns. It is nevertheless possible for each organic matter type (solid or solute) to have different $\mathrm{C}: \mathrm{N}: \mathrm{P}: \mathrm{O}: \mathrm{H}$ ratios in each column. These individual ratios must, however, remain constant with time.

The framework system must be completed with the specific parts required for a particular application to build a working instance of MEDUSA. This includes the requested composition in terms of solids and solutes, the reaction network of the diagenetic processes to consider, and the chemical equilibria between components of solute systems. MEDUSA must also be aware of the material characteristics such as densities, molar compositions and some thermodynamic properties for solid components or diffusion coefficients for solutes. Rate laws for the different processes under consideration need to be specified.

The information that is required for producing the Fortran code is collected in a series of XML files that define the composition of the sediment and describe the components, processes and equilibria to be considered. These are processed by the MEDUSA COnfigurator and COde GENerator, MEDUSACOCOGEN, to generate things as diverse as modules providing index parameters to address single components by meaningful names, subroutines to calculate molar masses of the components, subroutines to evaluate reaction rates of all the components and the corresponding derivatives with respect to the relevant component concentrations, and modules to ensure the $\mathrm{I} / \mathrm{O}$ to NetCDF files. The complete diagenesis model is bundled into an object library (libmedusa.a) to be linked with the application (host model).

\subsection{MEDUSACOCOGEN: the MEDUSA COnfigurator and COde GENerator}

The "Reference Guide to the Configuration and Code Generation Tool MEDUSACOCOGEN" in the Supplement provides an exhaustive description of the procedure to follow to build a working MEDUSA application. The formats of the required files are described in full detail with commented examples. The library of rate law functions and equilibrium relationships is also presented in detail. Further information can be found in the example applications provided in the code. Here, only a general overview of the functionality of the code generator is presented.

\subsubsection{Main building list}

The main building list provides the names of the description files of the solids, solutes and solute systems to consider in a particular model configuration, as well as the process and the equilibrium description file names.

\subsubsection{Sediment components: solids, solutes and solute systems}

Components (solutes or solids) can be of several types and be part of different classes. There are three types of components: ignored (default), normal or parameterised (for solutes only - see below). Evolution equations are only generated for normal components.

Solids actually encompass all the characteristics of solidphase components: their concentrations, their age or production time, and their isotopic signatures. A solid's description file provides information about its physical and chemical properties, such as intrinsic density, alkalinity content per mole (both mandatory), chemical composition and molar mass (optional). A solid can be part of one of four classes: basic solid (default), (particulate) organic matter, solid colour or solid production time. The basic solid class includes all physical solids but organic matter, be they reactive or not. For numerical stability reasons, it is mandatory to include at least one inert solid in the model sediment components to be flagged as mud. There is a dedicated class for organic matter offering special functionality. Chemical composition is mandatory for this class and can be set in terms of $\mathrm{C}: \mathrm{N}: \mathrm{P}$ ratios, from which the actual composition is then derived by $\mathrm{CH}_{2} \mathrm{O}, \mathrm{NH}_{3}$ and $\mathrm{H}_{3} \mathrm{PO}_{4}$ building blocks or completely in terms of the $\mathrm{C}: \mathrm{N}: \mathrm{P}: \mathrm{O}: \mathrm{H}$ composition. The solid colour class can be used for immaterial (volumeless) properties of solids, such as classical colour tracers or isotopic properties. Each component of this class is 
linked to another solid from which it inherits physical and chemical properties. For components in the solid production time class, the code generator produces adequate equations for age (concentration) tracers. These equations follow the Constituent-oriented Age and Residence time Theory, CART, developed by Delhez et al. (1999) and Deleersnijder et al. (2001). The CART approach provides a means to avoid numerical differentiation in the calculated evolution of the age tracer and the age-carrying component (and also between age tracers carried by different components) as the discrete representations of the underlying evolution equations of the age tracer and the age-carrying component have exactly the same structure and thus suffer from the same numerical dispersion. The original theory has been reformulated here in terms of production time instead of age. Production time is easier to handle than age in the evolution equations used in MEDUSA. That time remains constant in the absence of chemical reactions and mixing, whereas age will continue to evolve with time and thus require a sustained virtual advection or reaction, even if the material carrying the age tracer gets transferred to the CORELAY realm (where mixing and reactions are ignored). The amended theory is detailed in the technical report "Early Diagenesis in Sediments: A onedimensional model formulation" in the Supplement.

As mentioned above, there is a special type of solutes: $p a$ rameterised. For parameterised solutes, no evolution equations are generated. Their description files must therefore include a code snippet to calculate their abundance or to derive their value from specific boundary conditions. Typical examples of parameterised constituents are the calcium concentration, which can be derived from salinity, and the saturation concentration of $\mathrm{CO}_{3}^{2-}$ with respect to calcite, which can be calculated from the degree of saturation at the boundary or from the solubility product. The description files of normal solutes must include a code snippet to calculate the diffusion coefficient in free seawater. Solutes' descriptions must also include their specific alkalinity content per mole. There are only two classes of solutes: basic solute (default) and (dissolved) organic matter. Just like particulate organic matter, dissolved organic matter must be characterised by its chemical composition in terms of its $\mathrm{C}: \mathrm{N}: \mathrm{P}(: \mathrm{O}: \mathrm{H})$ ratios. For basic solutes, the chemical composition is optional.

Finally, a solute system is a set of solutes that MEDUSA considers a total sum in the equilibrium calculations. Typical examples of solute systems are DIC (dissolved inorganic carbon, composed of $\mathrm{CO}_{2}, \mathrm{HCO}_{3}^{-}$and $\mathrm{CO}_{3}^{2-}$ ) and the borate system $\left(\mathrm{B}(\mathrm{OH})_{3}\right.$ and $\left.\mathrm{B}(\mathrm{OH})_{4}^{-}\right)$. Solutes that are part of a solute system are considered to be in local chemical equilibrium with each other. Solute system description files simply list the description files of the solute components that make them up. The code generator internally compiles total alkalinity as a solute system based upon the specific alkalinity contents declared in the solute description files included in the model configuration.

\subsubsection{Processes and equilibria}

Description files for processes include a representation of the underlying chemical reaction that translates its effect on the various model constituents and specify the rate law to apply. MEDUSACOCOGEN currently provides 21 different rate law formulations (actually 30 as several of them have a few variants). Similarly, equilibrium description files must include a representation of the chemical equilibrium and specify the law of mass action to use for it. Expressions for laws of mass action (equilibrium relationships) require less variety than process rate laws: the four provided library routines cover the most common cases.

Rate laws and laws of mass action are provided in specially formatted Fortran 95 modules (so-called MODLIB files). The source code of a MODLIB file is preceded by a header (protected by a conditional inclusion pre-compiler directive) that provides meta-data helping to identify and classify the different parameters required. The module itself defines (1) a derived type structure that encapsulates the parameter values and relevant component index references and (2) a subroutine to evaluate the rate law expression and the equilibrium relationship, for given concentration and parameter values, and the derivatives with respect to the concentrations of the model components. MODLIB files for laws of mass action must further include a subroutine to set the equilibrium constant (currently derived from the boundary conditions) and another one to evaluate the scale applied to the equilibrium relationship. The current collection can be easily extended by adding MODLIB files to the library (for details about how to do this, please refer to the MEDUSACOCOGEN reference guide in the Supplement).

Chemical equilibria are always taken into account in the DBL and REACLAY realms. Processes are usually considered only in the REACLAY realm. However, processes involving only solutes can also be considered in the DBL. In addition, processes that represent radioactive decay of solid trace elements (i.e. of elements whose volume is considered negligible and that do therefore not impinge on the advection rate profile) should be declared to also apply in the TRANLAY and CORELAY realms (where reactions are normally stalled). This way, adequate corrections can be applied in the case that a sediment column becomes subject to chemical erosion and previously buried material gets remixed into the REACLAY realm. Without such corrections, the material returned to TRANLAY or REACLAY would appear too young.

\subsection{Code building and customisation options: taming the flexibility}

MEDUSA offers a great if not overwhelming deal of flexibility when it comes to setting up, building and running an early diagenesis application. That flexibility begins with the chemical composition (which can be freely chosen, except for a mandatory inert component), the reaction network 
and the chemical equilibria to consider, the handling of the components (normal or volumeless solids), and the physical processes at work (bioturbation and bioirrigation profiles). It goes on with the configuration of the model domain (its extent, its porosity profile and the resulting tortuosity, with or without a DBL, etc.) and the numerical (grid layout, upwinding scheme, etc.) and computational details (debugging output, choice of the coupling APIs, serial processing or MPIbased parallel processing, etc.).

In the following, a few of the most important of these options are shortly presented and discussed. Please refer to the MEDUSACOCOGEN reference guide and the technical report "Early Diagenesis in Sediments: A one-dimensional model formulation" in the Supplement for more detailed information about these and further options.

\subsubsection{Chemical composition and age tracking}

The sediment composition, the reaction network and the chemical equilibria to include in the model are obviously the first optional information to decide upon. For applications focusing on a given site or station, these are dictated by available data and observed processes; for MEDUSA applications designed to be coupled to a biogeochemical cycle model, they are defined by the concentration and flux boundary conditions that the host model can provide. When a MEDUSA application module is coupled to a biogeochemical model, it is possible to attach production time to one solid (or even several of them) in order to derive consistent "age models" for the synthetic sediment cores produced, thus providing means for meaningful comparisons to actual sediment core data. It should be noted, though, that attaching a time tracer to a solid requires all the processes relating to that solid to be duplicated. Since the execution time roughly scales as the square of the number of components, including one or more time tracers may significantly increase the computing time. If such a sediment module is only meant to provide a vertically resolved ocean-sediment exchange scheme, there is no need to include a time tracer.

\subsubsection{Volumeless solids}

The volumeless solids option was only introduced to allow the creation of applications that would, as far as possible, be compatible with other models that do not take the effect of chemical reactions on the advection rate profile into account (e.g. Boudreau, 1996; Soetaert et al., 1996; Jourabchi et al., 2008), but that rather link the advection rate profile directly to the porosity profile via $w(z) \varphi^{\mathrm{S}}(z)=w_{\mathrm{SWI}} \varphi_{\mathrm{SWI}}^{\mathrm{S}}\left(=w_{\infty} \varphi_{\infty}^{\mathrm{S}}\right)$. With this formulation, $w_{\mathrm{SWI}} / w_{\infty}$ is typically of the order of 2-3, whereas it can easily exceed 10 when the effects of chemical reactions are taken into account. In the test case applications presented in Sect. 3, the volumeless solids option is only used for the JEASIM application, which replicates a BRNS-global configuration (Jourabchi et al., 2008) that used such prescribed solids' advection rate profiles. As illustrated in that same application, this option may lead to physically unrealistic transport. The volumeless solids option should therefore only be used if absolutely required and with great care.

\subsubsection{Diffusive boundary layer}

An important option to decide upon is whether a DBL should be included or not. The existence of a DBL at the sea floor is merely due to the presence of a more or less sharply defined SWI that delimits the turbulent seawater medium. As such, it would actually seem a priori indispensable to include a DBL in any model configuration. Interestingly, early carbonate sediment models, such as that of Schink and Guinasso (1977), which were essentially designed to allow for an analytical solution, generally included a DBL. Similar subsequent models (e.g. Keir, 1982; Keir and Berger, 1983) did not include them anymore, possibly as a result of the adoption of non-linear calcite dissolution kinetics, which complicates the integration of a DBL (Munhoven, 1997). However, even in the later developed complex early diagenesis models, DBLs are not widespread, although the numerical solution schemes that they use can accommodate that complexity: CANDI (Boudreau, 1996) and OMEXDIA (Soetaert et al., 1996) are notable exceptions.

The equation system in the continuum part (i.e. REACLAY and DBL) of a MEDUSA column becomes "cleaner" at the SWI once a DBL is included: without a DBL the SWI lies on a grid node, which is ideal for a prescribed concentration boundary condition (used for solutes) but less so for a flux boundary condition (used for solids); with a DBL, the SWI lies on a grid vertex, which is perfect for solids and solutes alike in this case, as both then have to fulfil flux continuity conditions there. However, integrating a DBL into the model geometry also requires information about its thickness. A DBL acts as a transport barrier for the exchange of solutes between the sediment and the overlying seawater: the thicker it is, the stronger the resistance it exerts. For site-specific applications, that information may be derived from solute profiles if they are sufficiently precise. For global applications the situation is more complicated. DBL thicknesses at the sea floor range between 100 and $10000 \mu \mathrm{m}$, with a most probable value close to $1000 \mu \mathrm{m}$ (Sulpis et al., 2018). A typical thickness of $1000 \mu \mathrm{m}$ is probably adequate as a first approximation. The effects of a 100 and a $10000 \mu \mathrm{m}$ thick DBL might, however, be sensibly different.

All in all, it seems recommendable to include a DBL in model set-ups, especially when information about its thickness is available. For backwards compatibility with the interfaces to several biogeochemical cycle models that MEDUSA has been coupled to and that link to MEDUSA's SUBVERSION code repository for this purpose, the default in the code will nevertheless remain "no DBL" for the time being. 


\subsubsection{Other standard options and settings}

Most of the options discussed above either directly impinge on the code generated (composition, reaction network, equilibria, volumeless solids, choice of coupling API, selection of MPI processing, etc.) or have to be selected and defined before compilation (number of nodes for the DBL and REACLAY grids, etc.). Others can be selected and configured at runtime via specific configuration files, such as the grid point distribution function (six different formulations provided), the porosity profile (two different ones provided), the tortuosity parameterisations (three different ones provided), the biodiffusion constant's profile (seven options), the bioirrigation constant's profile (two options) and the upwinding scheme (two options). For several of these, special APIs are furthermore provided to manage custom formulations.

\section{Test case applications}

Three applications have been selected to illustrate the functionality of MEDUSA: (1) a replication of the ALL simulation experiment from Munhoven (2007), supplemented with an extended configuration that attaches an age tracer to calcite; (2) a coupling simulator wherein the boundary conditions that would normally be provided by a biogeochemical model that MEDUSA would be coupled to are read from a file; and (3) a MEDUSA configuration with complex composition and reaction network as considered in state-of-the-art early diagenesis models used for the analysis of site observational data. All of the test case applications use $\alpha \equiv 0$ (no bioirrigation).

\subsection{MEDMBM-PT - coupled simulation experiment with chemical erosion and resolved sedimentary records}

MEDUSA produces truly resolved and, via its CART-based age-production time control system, consistently dated synthetic sedimentary records. In order to illustrate the potential of this combination of features, the ALL experiment from Munhoven (2007) is repeated here with a MEDUSA configuration equivalent to the one used in that study, extended to attach age control information to calcite particles.

\subsubsection{Application description}

Munhoven (2007) used MBM coupled to MEDUSA v1 to explore the implications of the rain ratio changes proposed to explain glacial-interglacial atmospheric $\mathrm{CO}_{2}$ variations (see e.g. Archer and Maier-Reimer, 1994) for the preservationdissolution pattern of carbonate over these timescales. MBM is an 11-box model of the carbon cycle in the ocean and the atmosphere. The ocean is subdivided into 10 reservoirs as a function of depth (surface, intermediate and deep layers), latitude (low latitude, northern and southern high latitudes) and ocean basins (Atlantic, Antarctic and Indo-Pacific). The ocean reservoirs each have a depth distribution derived from the hypsometric curve. MBM calculates the evolutions of DIC, total alkalinity (TA), phosphate (the limiting nutrient) and oxygen in the oceanic reservoirs and $p \mathrm{CO}_{2}$ in the atmosphere. In addition, $\delta^{13} \mathrm{C}$ and $\Delta^{14} \mathrm{C}$ are considered for all carbon-bearing tracers and fluxes. Organic carbon, calcite and aragonite are produced by biological activity in the surface reservoirs and settle down to the intermediate and deep reservoirs. Some of the organic matter gets remineralised in the water column, and the rest is transferred to the sediment; all of the carbonate rains down to the sea floor and enters the sediment. The coupled model includes 304 MEDUSA sediment columns with a $10 \mathrm{~cm}$ thick bioturbated surface mixed layer, distributed as a function of depth (one column for each $100 \mathrm{~m}$ depth interval of sea floor) over the five ocean basins delimited by the five surface reservoirs (North Atlantic, equatorial Atlantic, Antarctic, equatorial Indo-Pacific and North Pacific). A grid with 21 nodes was used for the sediment columns. The sediment composition is the same as in Munhoven (2007): the solid phase is composed of clay, calcite, aragonite and organic matter; pore-water solutes are $\mathrm{CO}_{2}, \mathrm{HCO}_{3}^{-}, \mathrm{CO}_{3}^{2-}$ and $\mathrm{O}_{2}$ as solutes, with the carbonate system being in thermodynamic equilibrium. Here, that composition is augmented by an age tracer carried by calcite. Processes taken into account are calcite and aragonite dissolution as well as oxic organic matter remineralisation. For the sake of simplification it is assumed that the particles' age does not influence their solubility, which allows for a straightforward generation of the required evolution equation terms by MEDUSACOCOGEN. The exact formulations of the rate laws and the adopted parameter values are given in Table 3. MBM furthermore considers carbonate accumulation on the continental shelf.

The main driving forces in the ALL experiment are (1) the changing shelf accumulation rates that depend on the extent of low-latitude flooded shelves, which depends in turn on the sea level whose history is prescribed, (2) the changing export rain ratio (i.e. the carbonate $\mathrm{C}$ to organic $\mathrm{C}$ in the biogenic export fluxes), whose evolution is prescribed as well and which is $40 \%$ lower at peak glacial than at peak interglacial times, and (3) the riverine $\mathrm{HCO}_{3}^{-}$inputs and atmospheric $\mathrm{CO}_{2}$ consumption rates, which are derived from Jones et al. (2002). The deep-sea sedimentary accumulation patterns adjust onto the DIC and TA variations induced by these three factors. Please refer to Munhoven (2007) for additional details and references.

\subsubsection{Results and discussion}

Simulation experiments were run over 240000 years with cyclically repeated forcings (temperature, sea level, rain ratio changes, weathering, etc.) with a 120000 -year period. Figure 2 shows two aspects of the surface sedimentary $\mathrm{CaCO}_{3}$ content. The top panel depicts the actual time-dependent evo- 
Table 3. Reaction rate law expressions and parameter values used for the MBM experiments. $C_{\mathrm{cs}}$ is the $\mathrm{CO}_{3}^{2-}$ concentration in seawater at saturation with respect to calcite and $C_{\text {as }}$ that for aragonite; $C_{\text {hox }}$ is the half-saturation concentration of $\mathrm{O}_{2}$ for the oxic remineralisation of organic matter. $(\ldots)^{+}$denotes the positive part of (...). The different reaction rates, $\hat{R}$, are expressed in terms of the dissolving-remineralised solid in $\mathrm{kg}\left(\mathrm{m}^{3} \text { total sediment }\right)^{-1}$. Concentrations of solids are expressed in $\mathrm{kg}\left(\mathrm{m}^{3} \text { solid sediment }\right)^{-1}$, and those of solutes are expressed in $\mathrm{mol}\left(\mathrm{m}^{3} \text { pore water }\right)^{-1}$.

\begin{tabular}{ll}
\hline Calcite dissolution & $\hat{R}_{\mathrm{cdis}}=k_{\mathrm{c}}(1-\varphi)[$ calcite $]\left(\left(1-\left[\mathrm{CO}_{3}^{2-}\right] / C_{\mathrm{cs}}\right)^{+}\right)^{4.5}$ \\
& with $k_{\mathrm{c}}=365.25 \mathrm{yr}^{-1}\left(=100 \% \mathrm{~d}^{-1}\right), C_{\mathrm{cs}}=C_{\mathrm{cs}}(S, T, p)$ \\
\hline Oxic OM remineralisation & $\begin{array}{l}\hat{R}_{\mathrm{Omox}}=k_{\mathrm{Ox}}(1-\varphi)[\mathrm{OrgM}]\left(\left[\mathrm{O}_{2}\right] /\left(C_{\mathrm{hox}}+\left[\mathrm{O}_{2}\right]\right)\right) \\
\text { with } k_{\mathrm{Ox}}=0.024 \mathrm{yr}^{-1}, C_{\mathrm{hox}}=20 \mu \mathrm{molL} \mathrm{L}^{-1}\end{array}$ \\
\hline Aragonite dissolution & $\begin{array}{l}\hat{R}_{\text {adis }}=k_{\mathrm{a}}(1-\varphi)\left[\operatorname{aragonite}_{(} C_{\mathrm{as}}-\left[\mathrm{CO}_{3}^{2-}\right]\right)^{1.87} \\
\text { with } k_{\mathrm{a}}=53.8 \mathrm{yr}^{-1}\left(\mathrm{~mol}^{-1} \mathrm{~m}^{3}\right)^{1.87}, C_{\mathrm{as}}=C_{\mathrm{as}}(S, T, p)\end{array}$ \\
\hline
\end{tabular}

lution of that content in the sedimentary mixed layer in the equatorial Indo-Pacific part of the model ocean (indistinguishable from that shown in Munhoven, 2007). The bottom panel shows the resulting sedimentary record (synthetic cores); each dot represents a $1 \mathrm{~cm}$ thick sample, and the crosses depict the composition of the surface mixed layer (the REACLAY realm) as a function of depth, most of which overprint each other as both age and material distributions are rather homogeneous there, especially at depths shallower than $4700 \mathrm{~m}$.

It should be noted that the black dots, which correspond to samples almost devoid of the time-carrying calcite component, provide only incomplete or unreliable information, and several of these may possibly overprint each other. The white and grey lines in the top panel respectively represent the evolutions of the carbonate compensation depth (CCD, defined here as the depth at which the carbonate dissolution rate is equal to the carbonate deposition rate) and the calcite saturation horizon $(\mathrm{CSH}$, i.e. the depth at which saturation with respect to calcite is reached). The two distributions are broadly similar but present noticeable differences. There is a systematic time lag of about 3 to $8 \mathrm{kyr}$, which is most discernible in the regions where $\% \mathrm{CaCO}_{3}$ exceeds $70 \%$. This time lag is due to the fact that the age tracer tracks the average age of the surface sediment at burial, which is different from zero at all times. Another important difference is the alteration of the actual evolution (Fig. 2a) in the sedimentary record (Fig. 2b). The most striking differences are visible during times of shoaling $\mathrm{CCD}$ at depths at which $\% \mathrm{CaCO}_{3}$ is lower than $70 \%$. As shown by the long dashed line in Fig. 2b, which traces the evolution of the limit between the maroon and black zones from Fig. 2 a (the $0 \%$ calcite line) shifted by $5 \mathrm{kyr}$ towards the greater ages to account for the average calcite burial age, up to $20 \mathrm{kyr}$ of calcite history has been deleted from the record between 4700 and $6700 \mathrm{~m}$ b.s.l. due to chemical erosion.

MEDUSA always includes, at least internally, a TRANLAY-CORELAY stack of sediment layers underneath the REACLAY realm in order to handle possible chemical erosion events. These layers can a priori only be approximately dated from the recorded time of burial for each layer, i.e. the time when a given layer is separated from TRANLAY and transferred to CORELAY. With the CART-based production time information attached to a solid constituent, this shortcoming can be overcome.

\subsection{COUPSIM - coupling simulator}

MEDUSA has already been coupled to several ocean biogeochemistry and Earth system models. First results have been published for the coupling to the Community Earth System Model, CESM (Kurahashi-Nakamura et al., 2020); other coupling projects are well advanced (Moreira Martinez et al., 2016; Völker et al., 2020).

To illustrate the procedure of coupling MEDUSA to a biogeochemical model and to assess the computational cost of a typical sediment module for a real three-dimensional ocean biogeochemistry model, a coupling simulator, COUPSIM, was developed wherein the boundary conditions that would normally be provided by the host biogeochemical model are read from a file.

\subsubsection{Application description}

COUPSIM uses results obtained with the coupled Biogeochemistry-Ecosystem-Circulation model, BEC (Moore et al., 2004), ${ }^{3}$ that were made publicly available (Moore et al., 2005) in the framework of the Synthesis and Modelling Project of the US Joint Global Ocean Flux Study (US JGOFS) research programme. That version of BEC consists of a marine ecosystem model coupled to a preliminary version of the Community Climate System Model (CCSM 2.0) Parallel Ocean Program (POP). The coupling simulator was designed to run with annual or multi-annual time steps. The required forcing data were therefore extracted from the provided monthly mean datasets and aggregated into a yearly average climatology.

\footnotetext{
${ }^{3}$ Later references (e.g. Moore et al., 2013) resolve BEC as biogeochemical elemental cycling.
} 


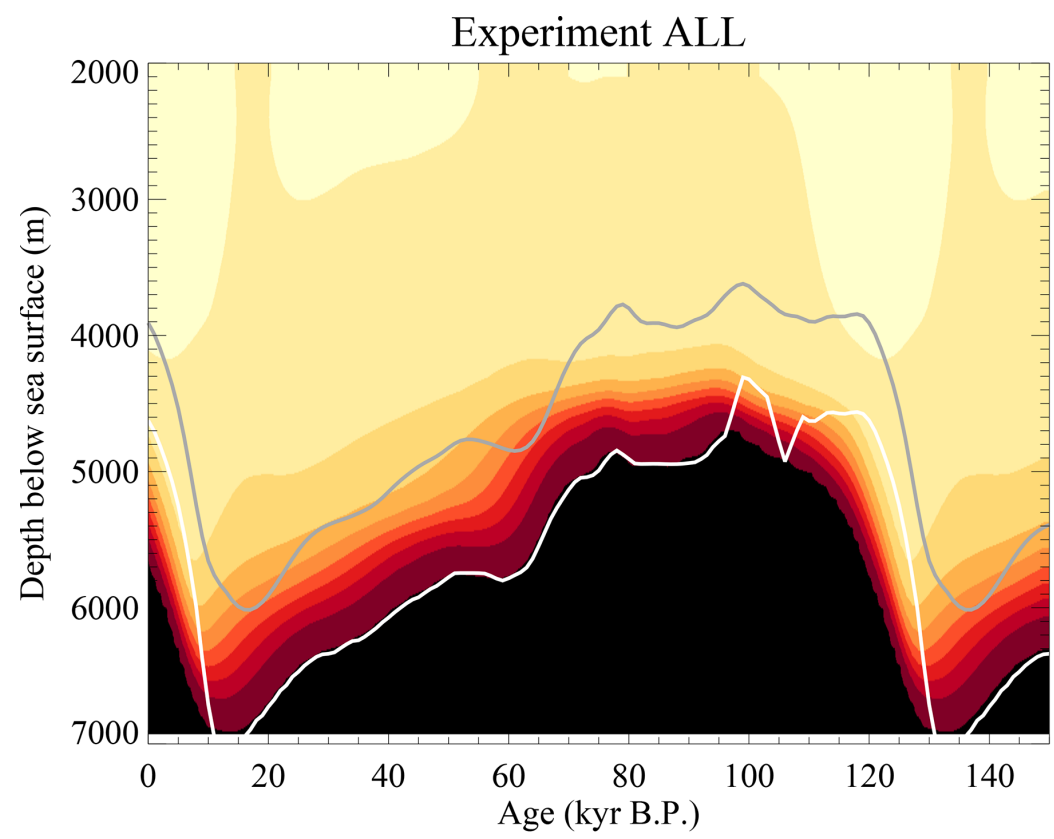

(a)
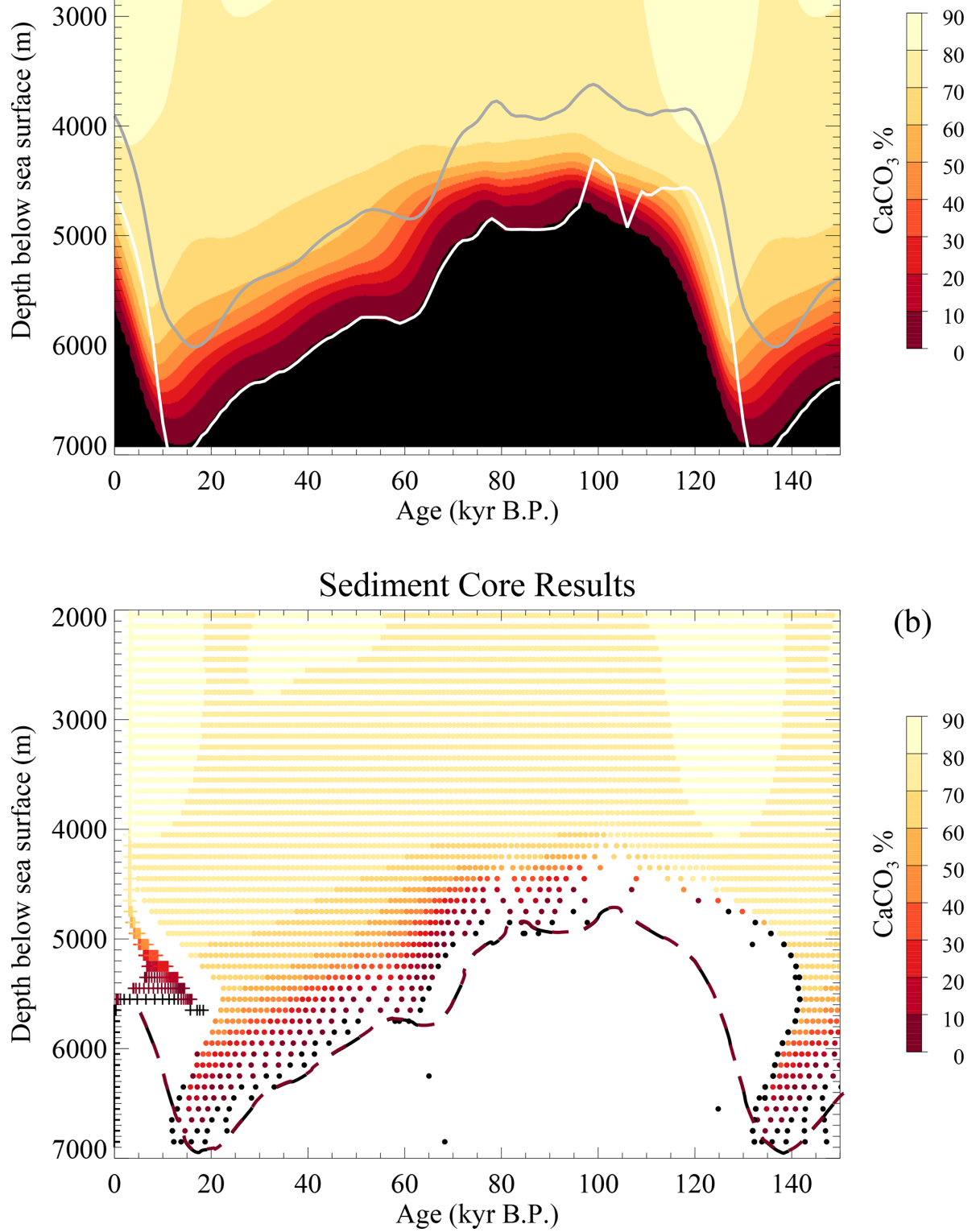

Figure 2. Average surface sediment $\mathrm{CaCO}_{3}$ content for the ALL experiment from Munhoven (2007). (a) Actual surface sediment \%CaCO 3 as a function of time. The grey line traces the evolution of the calcite saturation horizon (CSH), and the white line traces the carbonate compensation depth (CCD) at which the dissolution rate equals the deposition rate. (b) Synthetic sediment core record from cores "drilled" at $100 \mathrm{~m}$ sea-floor depth intervals from 2050 to $6850 \mathrm{~m}$ b.s.l. in the low-latitude Indo-Pacific box as a function of age of the layers. The long dashed line indicates the limit between the black and maroon zones in panel (a), shifted by 5 kyr to the right.

A MEDUSA configuration with four solid (clay, calcite, organic matter and opal) and six solute components $\left(\mathrm{CO}_{2}\right.$, $\mathrm{HCO}_{3}^{-}, \mathrm{CO}_{3}^{2-}, \mathrm{O}_{2}, \mathrm{NO}_{3}^{-}$and $\mathrm{H}_{4} \mathrm{SiO}_{4}$ ) was chosen. The processes considered are calcite dissolution, oxic respiration of organic matter, organic matter degradation by nitrate reduction, and full denitrification and opal dissolution. The exact rate law expressions used are given in Table 4. The model sediment columns are supposed to extend over the typical bioturbated mixed layer depth of about $10 \mathrm{~cm}$ throughout, covered by a grid with 21 nodes. The vertical resolution of the sediment column is thus of the same order as that of the water column in BEC, which has 25 vertical 
layers. MEDUSA sediment columns were attached to seafloor grid elements at depths greater than $1000 \mathrm{~m}$ below sea level, which amounted to 7332 globally. COUPSIM works perfectly well at shallower depths, ${ }^{4}$ but the BEC boundary conditions lead to completely unrealistic sediment compositions there, such as organic carbon contents of $40 \%$ or more over widespread areas. The BEC set-up used by Moore et al. (2004) calls upon a reflective boundary condition at the sea floor: all of the biogenic material that reaches the bottommost ocean cells gets entirely remineralised there. Shortcomings of that approach have already been mentioned in the Introduction. Here, another important one has to be added: remineralisation or dissolution rates, which normally change gradually with depth in the water column, present a sudden increase from the second deepest to the deepest layer, often by an order of magnitude, in some instances even by 2 or more. The dissolution flux in the bottom cells thus has two contributions: one part stems from the dissolution in the water column covered by the bottom cell and one part is related to the reflective boundary condition. To separate these two parts, the water column dissolution flux profile is therefore extrapolated to the bottom cells, assuming an exponential decrease with depth, using the values in the two ocean cells overlying each ocean bottom cell. The total bottom dissolution flux is then corrected for this water column dissolution part and the rest is supposed to settle at the sea floor where it enters the surface sediment.

\subsubsection{Results and discussion}

Reaction rate constants for the different processes have been adjusted in order to derive surface average sediment compositions that come as close as possible to observed distributions. For this adjustment process, the values of the parameters in the dissolution and remineralisation rate laws were varied and the model run to steady state for each parameter set.

The resulting global distributions of the solid fractions of calcite, total organic carbon and opal (respectively denoted $\%$ Calcite, \% TOC and \%Opal hereafter) were then evaluated against observational data (Seiter et al., 2004) on the basis of their respective standard deviations and correlation coefficients. The results of these experiments are summarised in the Taylor diagram (Taylor, 2001) in Fig. 3. For that diagram each one of the three distributions was normalised with respect to the standard deviation of its respective observational counterpart in order to be able to report all the results on a common scale. The peculiar distributions of the different characteristic points on that diagram indicate that there is a structural incompatibility between the data and the possible model results. Calcite points cluster around a correlation co-

\footnotetext{
${ }^{4}$ Please see the "Reply on RC1" in the Geoscientific Model Development Discussion version of this paper (https://doi.org/10.5194/gmd-2020-309-AC1) for instructions on how to verify this.
}

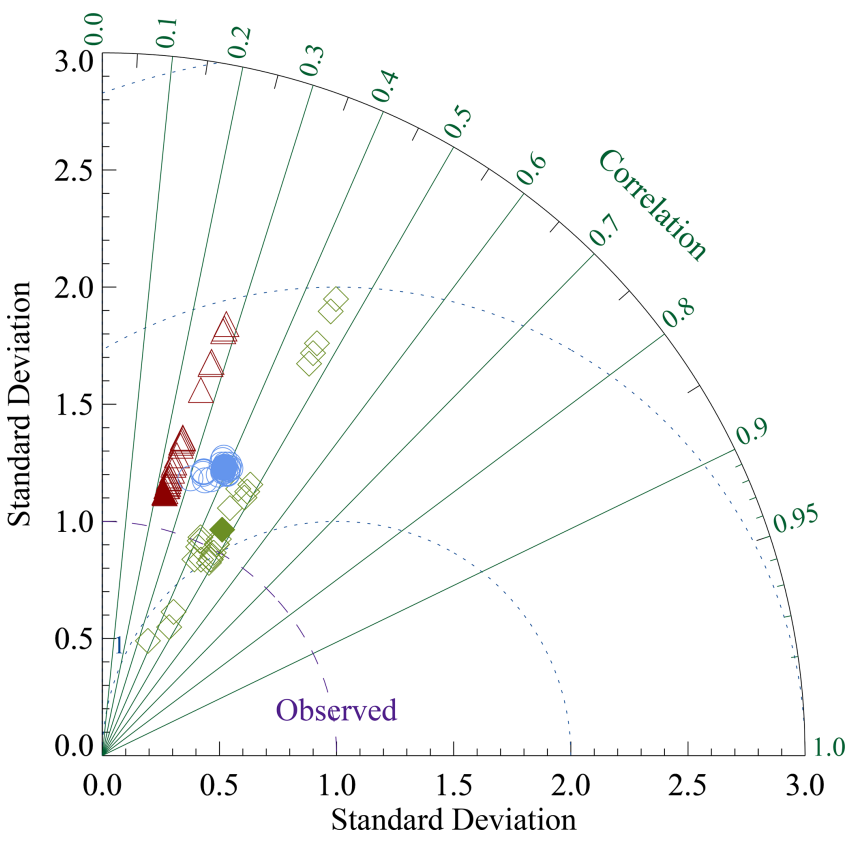

Figure 3. Taylor diagram showing the results of the parameter sensitivity experiments carried out with COUPSIM: \%Calcite (blue circles); \% TOC (green diamonds); \%Opal (red). The full symbols indicate the combination found for the best-fit experiment. Maps for the surface sediment compositions of this best-fit experiment are shown in Fig. 4.

efficient of 0.38 and a standard deviation of 1.3 , despite a large range of values $\left(5-1000 \% \mathrm{~d}^{-1}\right)$ used for the dissolution rate constant $\left(k_{\mathrm{c}}\right.$ in Table 4$)$ in the experiments. The opal and organic carbon points align on two beams with correlation coefficient values between 0.23 and 0.27 and between 0.35 and 0.45 , respectively, each one with a large range of standard deviations. For the organic matter dissolution rate laws values between 0.005 and $0.032 \mathrm{yr}^{-1}$ were adopted independently for the two rate constants ( $k_{\mathrm{ox}}$ and $k_{\mathrm{nr}}$ in Table 4$)$; for opal dissolution, rate constant values between 0.04 and $0.07 \mathrm{yr}^{-1}$, together with asymptotic concentrations ranging between 500 and $700 \mu \mathrm{mol} \mathrm{L}^{-1}$, were used $\left(k_{\mathrm{o}}\right.$ and $C_{\mathrm{os}}$ in Table 4).

Among all the experiments carried out, the one that offered the best compromise in terms of standard deviations coming as close as possible to the observations (i.e. to 1 after the normalisation) and maximising the correlation was selected as the best-fit experiment. The corresponding results are represented by the full symbols in Fig. 3. That experiment is characterised by a calcite dissolution rate constant of $36.525 \mathrm{yr}^{-1}$ (i.e. $10 \% \mathrm{~d}^{-1}$, only $1 / 10$ th of the $100 \% \mathrm{~d}^{-1}$ in Archer, 1991). For organic matter remineralisation the bestfit rate constants are 0.015 and $0.005 \mathrm{yr}^{-1}$ for oxic respiration and oxidation by nitrate reduction, respectively. These values compare well with the results of Palastanga et al. (2011), who also adopt a $1 \mathrm{G}$ approach but use different rate constants at 
Table 4. Reaction rate law expressions adopted for COUPSIM and parameter values for the experiment depicted in Fig. 4 (represented by the full symbols in Fig. 3). Units and notations are the same as in Table 3 . In addition, $C_{\mathrm{hnr}}$ is the half-saturation concentration of $\mathrm{NO}_{3}^{-}$and $C_{\text {io }}$ the characteristic inhibition concentration of $\mathrm{O}_{2}$ for the oxidation of organic matter by nitrate reduction.

\begin{tabular}{|c|c|}
\hline Calcite dissolution & $\begin{array}{l}\hat{R}_{\mathrm{cdis}}=k_{\mathrm{c}}(1-\varphi)[\text { calcite }]\left(\left(1-\left[\mathrm{CO}_{3}^{2-}\right] / C_{\mathrm{cs}}\right)^{+}\right)^{4.5} \\
\text { with } k_{\mathrm{c}}=36.525 \mathrm{yr}^{-1}\left(=10 \% \mathrm{~d}^{-1}\right), C_{\mathrm{cs}}=C_{\mathrm{cs}}(S, T, p)\end{array}$ \\
\hline Oxic OM remineralisation & $\begin{array}{l}\hat{R}_{\mathrm{Omox}}=k_{\mathrm{Ox}}(1-\varphi)[\mathrm{OrgM}]\left(\left[\mathrm{O}_{2}\right] /\left(C_{\mathrm{hox}}+\left[\mathrm{O}_{2}\right]\right)\right) \\
\text { with } k_{\mathrm{Ox}}=0.015 \mathrm{yr}^{-1}, C_{\mathrm{hox}}=3 \mu \mathrm{molL}^{-1}\end{array}$ \\
\hline OM remin. by nitrate reduction & $\begin{array}{l}\hat{R}_{\mathrm{Omnr}}=k_{\mathrm{nr}}(1-\varphi)[\mathrm{OrgM}]\left(\left[\mathrm{NO}_{3}^{-}\right] /\left(C_{\mathrm{hnr}}+\left[\mathrm{NO}_{3}^{-}\right]\right)\right)\left(C_{\mathrm{io}} /\left(C_{\mathrm{io}}+\left[\mathrm{O}_{2}\right]\right)\right) \\
\text { with } k_{\mathrm{nr}}=0.005 \mathrm{yr}^{-1}, C_{\mathrm{hn}}=30 \mu \mathrm{molL}^{-1}, C_{\mathrm{io}}=10 \mu \mathrm{molL}^{-1}\end{array}$ \\
\hline Opal dissolution & $\begin{array}{l}\hat{R}_{\text {odis }}=k_{\mathrm{o}}(1-\varphi)[\mathrm{opal}]\left(C_{\mathrm{os}}-\left[\mathrm{H}_{4} \mathrm{SiO}_{4}\right]\right)^{+} \\
\text {with } k_{\mathrm{o}}=0.05 \mathrm{yr}^{-1} \mathrm{~mol}^{-1} \mathrm{~m}^{3}, C_{\mathrm{os}}=700 \mu \mathrm{molL}^{-1}\end{array}$ \\
\hline
\end{tabular}

depths shallower than $2000 \mathrm{~m}\left(k_{\mathrm{ox}}=0.01 \mathrm{yr}^{-1}\right.$ and $k_{\mathrm{anox}}=$ $\left.0.008 \mathrm{yr}^{-1}\right)$ and greater than $2000 \mathrm{~m}\left(k_{\mathrm{ox}}=0.005 \mathrm{yr}^{-1}\right.$ and $\left.k_{\text {anox }}=0.002 \mathrm{yr}^{-1}\right)$. For opal, a comparatively high value of $0.05 \mathrm{yr}^{-1}\left(\mathrm{~mol} \mathrm{~m}^{-3}\right)^{-1}$ had to be adopted in order to avoid widespread opal-dominated sea-floor sediments. For comparison, the rate constant of $30 \mathrm{yr}^{-1}$ in Boudreau (1990) translates to $0.0034 \mathrm{yr}^{-1}\left(\mathrm{~mol} \mathrm{~m}^{-3}\right)^{-1}$ for the rate law formulation adopted here. The asymptotic ("saturation") concentration for opal dissolution had to be set to $700 \mu \mathrm{M}$, which ranges at the cold-water end $\left(\leq 1^{\circ} \mathrm{C}\right)$ of the experimentally derived values of Dixit et al. (2001).

The resulting average surface model sediment composition at steady state is compared to the target data of Seiter et al. (2004) in Fig. 4. Calcite-rich sediments are produced in the Indian and South Pacific; the calcite-rich sediments along the Atlantic mid-ocean ridge are only reproduced in the South Atlantic and at mid-latitudes in the North Atlantic. The sediments that are richest in TOC are located in the equatorial eastern Pacific. The opal belt in the Southern Ocean stands out, as does the maximum in the equatorial eastern Pacific. This latter is, however, too narrow and, similarly to the calcite maxima, too sharply delimited.

Among the structural incompatibilities, the band of calcite-rich sediments along the entire rim of the Pacific Ocean in the Northern Hemisphere stands out. These are not seen in the data for the simple reason that the CSH is actually shallower than $1000 \mathrm{~m}$ almost everywhere along this band, except in the Sea of Japan (or East Sea) (Yool et al., 2001). In the BEC results, this whole band is supersaturated with respect to calcite. No parameter combination can override this supersaturation and significantly reduce the amount of carbonate preserved. The reflective boundary condition actually contributes to this unrealistic supersaturation, possibly even causes it: as all of the calcite that reaches the deepest ocean cells there unconditionally dissolves, the degree of supersaturation of the bottom waters is artificially increased. In the coupled CESM-MEDUSA model experiment of KurahashiNakamura et al. (2020), this carbonate-rich band is not produced. Another important feature of the model \%Calcite is the absence of carbonates at the sea floor in the Atlantic north of the Equator and south of $30^{\circ} \mathrm{N}$, again in contradiction to the data. This results from very low $\mathrm{CaCO}_{3}$ deposition rates of the order of $1-3 \mathrm{~g} \mathrm{~m}^{-2} \mathrm{yr}^{-1}$, combined with high lithogenic deposition rates of the order of $15 \mathrm{~g} \mathrm{~m}^{-2} \mathrm{yr}^{-1}$ in the BEC results, which caps \%Calcite at about 5\%-15\% a priori even in the absence of dissolution. The extended areas of carbonate-rich sea-floor sediments along the North Pacific rim and of strongly diluted sediments in the central Atlantic contribute to the poor correlation coefficient, whatever the model parameter combinations chosen.

In general, the model sediment compositions show far more pronounced contrasts than the observed ones. In all three distributions, the more diffuse features of the global distributions seen in the data are missing. Intermediate values are widespread in the observed distributions, especially for organic carbon for which there are only a few isolated spots at the upper end of the depicted range. The model produces surface sediments in most regions that are either poor or extremely rich in calcite. There are only few areas with calcite fractions between $20 \%$ and $80 \%$. The same holds for organic carbon and opal, albeit to a lesser degree for the latter, which presents more extended areas with intermediate abundances.

The sharp contrasts for \%Calcite can be partly explained by the vertical grid resolution of the BEC version used by Moore et al. (2004). The CSH in the South Pacific is situated at a depth of about $2.5-3.3 \mathrm{~km}$ and at about $3-3.7 \mathrm{~km}$ in the Indian Ocean (Yool et al., 2001). At these depths, the vertical resolution of BEC is about $340-450 \mathrm{~m}$. As the transition zone from carbonate-rich to carbonate-poor sediment depths is about $500 \mathrm{~m}$ thick there, it is clear that this transition zone cannot be satisfactorily resolved. There are several options to alleviate this shortcoming. The most obvious one is of course to increase the vertical resolution of the host model. The CESM version used by Kurahashi-Nakamura et al. (2020) has 60 vertical levels. Another option would be to call upon sub-grid-scale depth profiles and to attach several (two to four) sediment columns to each model sea-floor grid ele- 

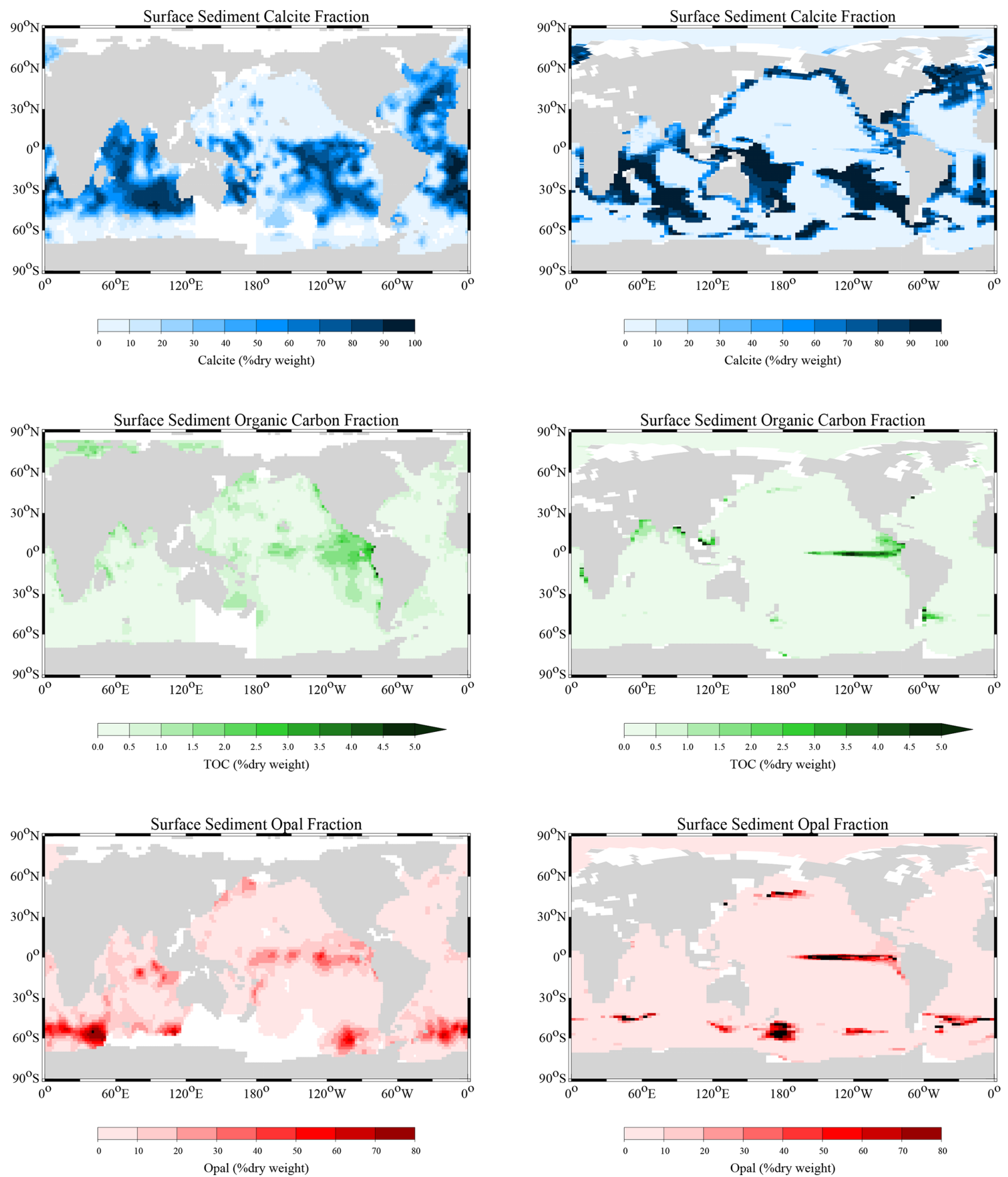

Figure 4. Left column: data (Seiter et al., 2004) binned to a $2^{\circ} \times 2^{\circ}$ resolution comparable to the average resolution of BEC; right column: COUPSIM (i.e. MEDUSA forced by the BEC model results of Moore et al., 2004).

ment. This would of course increase the computational burden of the sediment part of the model, but as can be deduced from the execution times reported and discussed below, these would not represent a major hindrance given the efficiency of the numerical procedures adopted in MEDUSA.
The \%Opal distribution is essentially correlated with the deposition flux rates of opal, which themselves present a highly contrasting distribution. \% TOC appears to depend on the organic deposition flux rate and the bottom water oxygen distribution. The preservation tongue in the equatorial east- 
ern Pacific results from a well-delimited deposition rate maximum, in combination with middle to low oxygen concentrations $\left(20-160 \mu \mathrm{molL}^{-1}\right)$. The high organic deposition rates in the Southern Ocean and along the west coast of Africa, on the other hand, do not lead to high \% TOC as these regions are much better oxygenated $\left(160-250 \mu \mathrm{molL}^{-1}\right)$.

\subsubsection{Execution times}

The execution times for the best-fit experiment for different computing environments (serial, with the 2D coupling API, parallel, with MPI and the 1D or the 2D coupling API) are reported in Table 5. MPI-2D $\times 2 \mathrm{D}$ execution times, i.e. execution times for the $2 \mathrm{D} \times 2 \mathrm{D}$ API with MPI enabled, are not reported as they are always within a few percent of those for MPI-2D. The results discussed above were for steady state, i.e. one infinitely long time step. To assess the computational overburden of typical experimental runs, execution times for a 1000-year simulation experiment were also investigated, with sediment model steps ranging from 1 to 1000 years. To allow for an easier comparison, the execution times are reported relative to the serial experiment with 100 time steps of 10 years, which took 9:14.73 $\mathrm{min}$ on the computing platform used for the experiments. The usage of 1-year time steps makes this serial experiment last 7.7 times longer (1:11:09 h). Parallel execution allows a considerable reduction of these execution times: with two processors, the execution time of the reference experiment is reduced by $38 \%$ and by $68 \%$ with four processors (using the MPI-2D API). Relative reductions are nearly the same for the simulations with a 1-year time step. The 1D coupling API, which offers the best workload balance with MPI in theory as the sediment columns can be optimally distributed among the processes, is about $10 \%-20 \%$ less efficient than the MPI-2D API, which offers a poorer workload balance in theory, because of a more complicated coordination overhead. All in all, we may expect the computational overburden of MEDUSA to represent only a small fraction of the total execution time of a complex Earth system model.

\subsection{JEASIM - complex composition and reaction network model}

In order to compare the performance of MEDUSA to that of other state-of-the-art early diagenesis models, the study of Jourabchi et al. (2008) was revisited. These authors used the Biogeochemical Reaction Network Simulator, BRNS (Jourabchi et al., 2005), to analyse sea-floor sediment $\mathrm{O}_{2}$ and $\mathrm{pH}$ profile data from 13 different sites. The model description in Jourabchi et al. (2008) is sufficiently detailed and complete to allow a meaningful replication.

\subsubsection{Application description}

Here the original model configuration is simplified by neglecting the sulfurous constituents (sulfate and sulfide) and methane as well as the sulfur-based processes (sulfate reduction, sulfide oxidation) and methanogenesis. Jourabchi et al. (2008) found that these were significant at a few sites only (their sites 40, 48 and 120). Furthermore $\mathrm{H}^{+}$and $\mathrm{OH}^{-}$are not explicitly considered, but their effects are implicitly included in the combined carbonate and borate equilibria, similarly to Van Cappellen and Wang (1996). The adopted model configuration thus includes $\mathrm{CO}_{2}, \mathrm{HCO}_{3}^{-}, \mathrm{CO}_{3}^{2-}, \mathrm{O}_{2}, \mathrm{NO}_{3}^{-}$, $\mathrm{Mn}^{2+}, \mathrm{Fe}^{2+}, \mathrm{NH}_{4}^{+}, \mathrm{B}(\mathrm{OH})_{3}$ and $\mathrm{B}(\mathrm{OH})_{4}^{-}$as solutes, two classes of organic matter, clay, calcite, $\mathrm{MnO}_{2}$ and $\mathrm{Fe}(\mathrm{OH})_{3}$ as solids. The primary redox reactions considered are organic matter oxidation by oxic respiration, by nitrate reduction and denitrification, by $\mathrm{Mn}$ (IV) reduction, and by $\mathrm{Fe}$ (III) reduction, each one duplicated for the two classes of organic matter. The secondary redox reactions considered are nitrification, $\mathrm{Mn}^{2+}$ and $\mathrm{Fe}^{2+}$ re-oxidation by $\mathrm{O}_{2}$, and $\mathrm{Fe}^{2+}$ reoxidation by $\mathrm{MnO}_{2}$. Furthermore, calcite dissolution is included. The carbonate and borate systems are kept in equilibrium. The resulting application is called JEASIM (Jourabchi Et Al. SIMplified).

Unlike BRNS-global, MEDUSA is based upon a complete composition approach with regard to solids: it is assumed that the composition of the solid phase is completely known and the solids' advection rate profile is deduced from the porosity and the reaction rate profiles (see Eq. 3). Jourabchi et al. (2008) do not consider the effect of chemical reactions on the solid advection rate profile but only set the burial velocity, from which the advection rate profile is then derived, assuming that reactions do not have any influence on the advection rate profile (i.e. the integral term in Eq. 3 is neglected). This behaviour can be simulated in MEDUSA by calling upon the volumeless solids option at compile time. With this option, only the main inert solid is considered to have a finite density. All the others are considered to be tracers without significant volume, but only mass (i.e. they have zero partial specific volume and infinite density). Both approaches are mathematically equivalent and both have an important drawback: they allow the transport of physically unrealistic amounts of non-inert material (e.g. calcite mass fractions exceeding $100 \%$ ), as will be seen below. The model sediment columns were assumed to extend down to $82 \mathrm{~cm}$ as in the original study; a REACLAY grid with 321 nodes was used, without a DBL. Porosity and bioturbation profiles were prescribed using the information provided by Jourabchi et al. (2008). Boundary and forcing conditions (solute concentrations, calcite saturation state at the SWI, solids' burial rate) were also taken from Jourabchi et al. (2008). For the purpose of this application, the solids' burial rate was converted to an equivalent flux of inert material (dubbed clay) across the SWI.

\subsubsection{Adjustment procedures}

The adjustment was carried out in two stages for each of the 13 stations. At the first stage, the organic matter deposi- 
Table 5. Execution times of the COUPSIM best-fit experiment. One unit of CPU time corresponds to 9:14.73 min here. The executing platform had an Ubuntu 16.04.6 LTS operating system (64 bit kernel 4.4.0-185-generic) running on a $1.90 \mathrm{GHz}$ Intel ${ }^{\circledR} \mathrm{Core}^{\circledR}$ i7-8650U CPU; the codes were compiled with GFortran 5.4.0 using optimisation level - 0 0. Experiments carried out with MPI enabled used Open MPI v. 1.10.2 and were run on as many processes as indicated in brackets.

\begin{tabular}{|c|c|c|c|c|c|c|}
\hline \multirow[t]{2}{*}{ Number of steps } & \multirow[t]{2}{*}{ Step length } & \multicolumn{5}{|c|}{ Wall-clock time (relative units) } \\
\hline & & Serial & MPI-1D (2) & MPI-2D (2) & MPI-1D (4) & MPI-2D (4) \\
\hline 1 & $\infty$ & 0.049 & 0.034 & 0.028 & 0.021 & 0.020 \\
\hline 1 & 1000 years & 0.028 & 0.020 & 0.016 & 0.012 & 0.010 \\
\hline 10 & 100 years & 0.17 & 0.12 & 0.097 & 0.079 & 0.065 \\
\hline 100 & 10 years & 1.0 & 0.73 & 0.62 & 0.47 & 0.42 \\
\hline 1000 & 1 year & 7.7 & 5.9 & 4.8 & 3.5 & 3.2 \\
\hline
\end{tabular}

tion rate and the degradation rate constants were adjusted in order to reproduce the measured oxygen concentration profiles; calcite dissolution was ignored. For the second stage, these two parameters were held fixed at the values obtained during the first stage. This time, the calcite deposition rate and the calcite dissolution rate constant were adjusted in order to reproduce the measured $\mathrm{pH}$ profiles. We only considered calcite dissolution rate orders 1,2 and 4.5 , disregarding the relatively uncommon order 0.5 . In contrast to Jourabchi et al. (2008), who adopted static initial values for the calcite dissolution rate constant, random perturbations to these were tested at the second step in order to allow a deeper exploration of the results space. In a few instances, this contributed to significantly improving on the results of Jourabchi et al. (2008). Fits were carried out with MPFIT (Markwardt, 2009) ${ }^{5}$ with the GNU Data Language (GDL v. 0.9.6). The minimisation procedure implemented in MPFIT is based upon the Levenberg-Marquardt algorithm. For the $\mathrm{pH}$ profile fitting, calculations were based upon $\mathrm{H}^{+}$concentrations derived from the $\mathrm{pH}$ data.

\subsubsection{Results and discussion}

$\mathrm{O}_{2}$ data are comparatively straightforward to fit. The model profiles obtained are essentially identical to those of Jourabchi et al. (2008), and they are therefore not discussed here. The detailed results can be found in the jeasim_vl.ods spreadsheet file in the work/jeasim directory of the code and data archive provided in the Supplement on the sheet named jeasim_adj0; the resulting $\mathrm{O}_{2}$ profile fits are shown in Figs. S1 and S2 in "Additional Results" in the Supplement. In terms of the relative misfits, the quality of the fits obtained here is even slightly superior in most instances to those of Jourabchi et al. (2008), except for site 2 , where ours is $37 \%$ worse. Three others (sites 19, 40 and 59) have similar relative misfits (within $\pm 10 \%$ of those in Jourabchi et al., 2008); all the rest present between $20 \%$ and $80 \%$ lower relative misfits.

\footnotetext{
${ }^{5}$ Available from http://purl.com/net/mpfit (last access: 27 May 2021).
}

The $\mathrm{pH}$ profile adjustments, on the other hand, were far less straightforward. A procedure with up to three steps was therefore adopted. First, the fitting procedure was carried out with only the $\mathrm{pH}$ profile data as a constraint. As mentioned above, the way the application is designed (with the volumeless solids option), physically unrealistic mass fractions exceeding $100 \%$ cannot be precluded a priori. The fits for 6 out of the 13 stations considered (shown in Fig. 5) were affected by this shortcoming. For these stations, the optimal calcite fraction in the total mass entering the sediment column at the SWI ranged between 140 and $5400 \%$ (see Table S1 in "Additional Results" in the Supplement). At sites 19 and 20, the resulting calcite mass fraction in the surface sediment solid fraction was nevertheless physically acceptable; at the four other stations it ranged between $330 \%$ and $4100 \%$. For sites 49 and 57 the optimal $\mathrm{pH}$ profiles are in poor agreement with the data. The same was observed by Jourabchi et al. (2008): for site 49 , they did not even report any $\mathrm{pH}$ results, and for site 57 , they only obtained a profile for the dissolution rate order 0.5 , which is not considered here. Here, fits for site 57 could be derived for each rate order considered. All of these strongly resemble the profile of Jourabchi et al. (2008) for $n=0.5$ and also fit the data in a similarly poor way.

For these six sites a second round of fits was performed with the calcite mass fraction in the total deposition flux at the SWI limited to $90 \%$. The $\mathrm{pH}$ profiles from these second fits (except for site 49, which is not considered any further), together with those of the other sites that passed the first step, are shown in Fig. 6. Sites 19 and 20 are again noteworthy as the calcite input limitation does not allow us to obtain any meaningful $\mathrm{pH}$ profile to fit the data for these. It should, however, be noted that Jourabchi et al. (2008) also obtained only physically unrealistic results for sites 19 and 20: the calcite deposition flux rates reported for these two sites in their Table 8 would actually require minimum advection rates at the SWI that exceed the prescribed ones by factors of 2.7 to 4.7 . For sites 40 and 48 , the $\mathrm{pH}$ profiles found here are essentially indistinguishable from those of Jourabchi et al. (2008) (although the profiles found for $n=1$ and $n=4.5$ at site 48 appear to be swapped). For sites 39 and 58, the sub- 

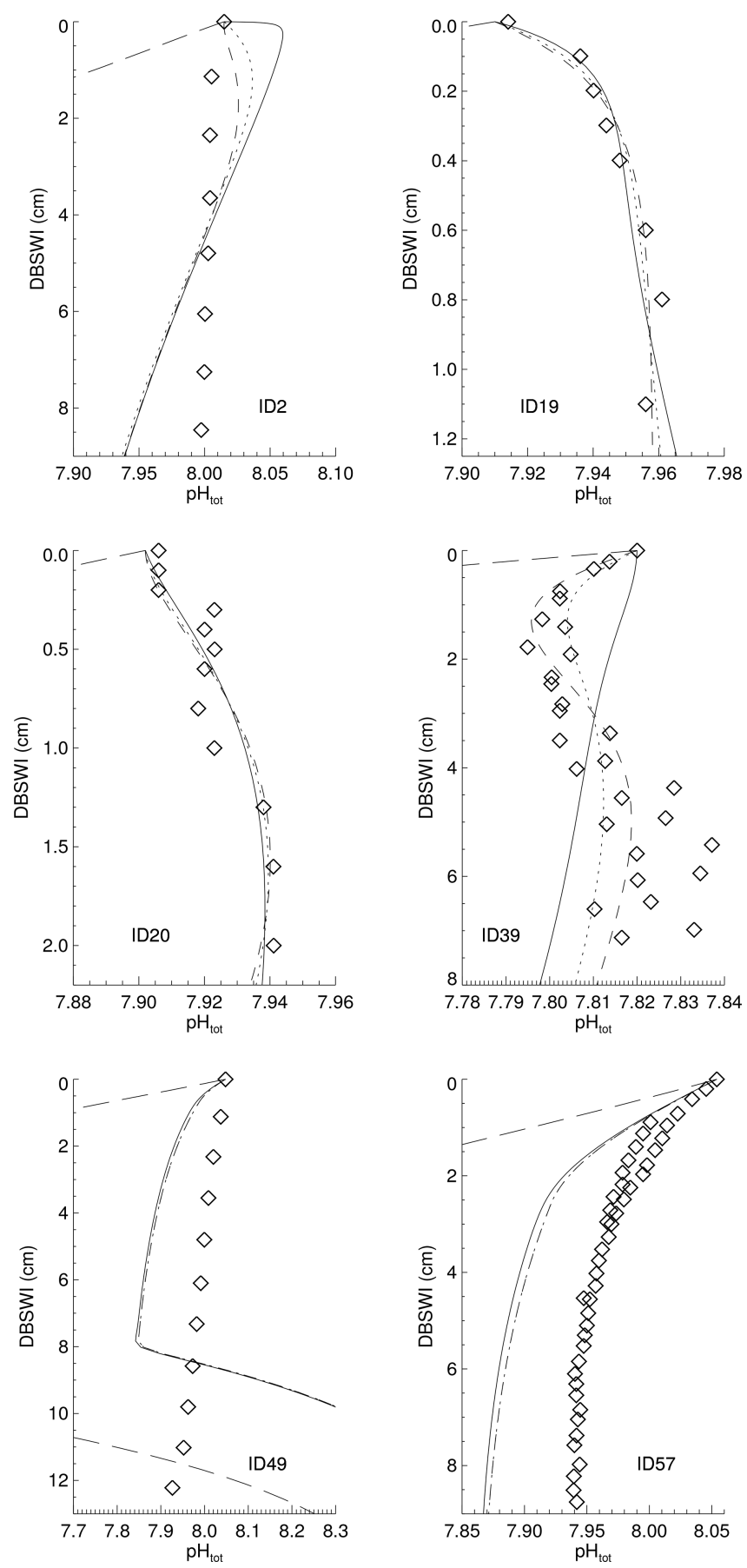

Figure 5. The $\mathrm{pH}$ profiles, unconstrained with respect to the calcite mass fraction in the deposition flux and in the surface solids, for stations that produced physically impossible fits (calcite mass fractions exceeding $100 \%$ either in the mass deposition flux or the solid concentration profile). Lines are as follows: long dashed - no calcite dissolution; full - calcite dissolution kinetics of order 4.5; dotted - order 2; short dashes - linear. surface minima found here are less pronounced than those in Jourabchi et al. (2008): at site 39, the fits for orders 1 and 2 are improved here but degraded for order 4.5 ; at site 58 all fits are better here as the data do not support well-pronounced subsurface minima. The optimised $\mathrm{pH}$ profiles obtained here yield better fits at site 41 for $n=1$ and $n=2$, but a worse one for $n=4.5$. The profile for $n=4.5$ exhibits a subsurface minimum that is too strong together with $\mathrm{pH}$ values that are too high at depth. However, attempts to improve the fit of the subsurface minimum deteriorates the quality of the fit at depth, increasing the overall relative misfit. All $\mathrm{pH}$ profiles derived here at site 50 are similar to those obtained by Jourabchi et al. (2008) or better. In particular, the profile for $n=4.5$ does not present a systematic bias towards lower $\mathrm{pH}$ values. At site 59, we obtain significantly better $\mathrm{pH}$ profile fits. For that site, Jourabchi et al. (2008) only found $\mathrm{pH}$ gradients at the SWI that were opposite to the observations with their model, whereas the gradients obtained here are in agreement with the data (for all calcite dissolution rate orders). For site 120 , our $\mathrm{pH}$ profiles do not present the bias towards low $\mathrm{pH}$ seen in the results of Jourabchi et al. (2008). They rather present a bias towards higher $\mathrm{pH}$ caused by the three outliers between 2.5 and $3 \mathrm{~cm}$ of depth: additional experiments (not shown) wherein these outliers were removed allowed us to improve the relative misfit by a factor of 4 . In addition, it has also been possible to produce a $\mathrm{pH}$ profile for $n=4.5$.

The inspection of the other characteristics of the resulting model sediment revealed that most of the sites presented calcite mass fractions that are far too low in the surface sediment (see Table S2 in "Additional Results" in the Supplement). Only at sites 39 and 57 does it come close to the observed $90 \%$. This is, however, most likely due to the imposed deposition flux with $90 \%$ calcite at these sites. In a third step, the experiments for all the sites were therefore repeated by adding the surface sediment calcite mass fraction as a constraint, letting the mass fraction of calcite in the deposition flux float again. For this purpose, the calcite fractions reported by Jourabchi et al. (2008, Table 1) were assumed to hold for the average over the top $10 \mathrm{~cm}$ of the sediment. The resulting $\mathrm{pH}$ profiles are shown in Fig. 7. The profiles obtained for sites 2, 19 and 20 require, once more, a few comments. They all apparently present more or less acceptably fitted $\mathrm{pH}$ profiles, which are only slightly worse than at the first step (Fig. 5) but far better than at the second step (Fig. 6). However, the constraint on the surface sediment mass fraction of calcite is unfortunately not sufficient to yield physically realistic results at these three sites. The calculated optimal calcite mass fractions in the deposition flux for all dissolution rate orders range from $140 \%$ to $730 \%$, except for site 2 , where $n=1$ and $n=2$ provide acceptable results, but not $n=4.5$ (see Table S3 in "Additional Results"). There is little difference between the fits with the limited calcite deposition flux at sites 39, 48, 50, 57, 58 and 120. At site 59 , for which the optimal $\mathrm{pH}$ profiles obtained at the previous step were superior to those obtained by Jourabchi et al. 
(2008), the gradients now change sign for $n=1$ and $n=2$, and the quality of the fits degrades; the quality of the profile obtained for $n=4.5$ is also sightly degraded but remains acceptable. At site 41, the differences are comparatively large, except for $n=4.5$. The reason for these contrasting changes is simple. The target \%Calcite is $87 \%$. During the first fitting exercise, the $\%$ Calcite was $77 \%$ for $n=4.5$ but only $0.04 \%$ and $0.06 \%$ for $n=2$ and $n=1$, respectively. Accordingly, these latter cases require strong increases in the calcite deposition rate combined with strongly reduced dissolution rates to meet that imposed constraint. All in all, the two models produce results in agreement with each other. Interestingly, the stations for which Jourabchi et al. (2008) diagnosed a significant role for sulfur-based processes yield optimal $\mathrm{pH}$ profiles here that are essentially identical than the original ones. This should not, however, be seen as proof that sulfate reduction and subsequent sulfide oxidation are negligible at the sites under study. It should indeed not be forgotten that the $\mathrm{O}_{2}$ and $\mathrm{pH}$ data profiles only cover the uppermost parts of the sediment pore waters, in some instances only the topmost 1-2.5 cm: for $\mathrm{O}_{2}$ these are the profiles at sites 2, 19, 20, 48 and 50, and for $\mathrm{pH}$ these are the profiles at sites 19, 20, 48 and 50. They thus provide only a weak constraint on the deeper parts of modelled sediment depth at which sulfatereduction-fuelled processes typically take place.

Although it would certainly be interesting to investigate the reasons for the failure to produce satisfactory fits to the $\mathrm{pH}$ data profiles with our models, this would go beyond the scope of this model description paper. Besides the simplifications in the sediment compositions and the reaction network, a few differences remain between BRNS-global and the JEASIM application of MEDUSA as well as between the adopted fitting procedures. The differences between the two models are expected to have only a minor impact. BRNSglobal takes the pore-water advection into account, whereas MEDUSA does not by default (as adopted here), since it is small compared to diffusive transport. The fitting procedures may have a more important impact. The optimisation routine used by Jourabchi et al. (2008) calls upon a simplex algorithm; MPFIT uses a Levenberg-Marquardt method and furthermore allows range constraints for the solutions to be taken into account. Both algorithms are iterative and suffer from inherent shortcomings. It is well known that the simplex method may converge to non-stationary points. With MPFIT, the a priori physically sufficient lower boundary of zero occasionally had to be increased to some non-zero positive value. The iterations eventually "bounced" upon this non-zero value and made the procedure converge to some well-pronounced minimum, whereas the theoretically sufficient bound of zero would have made the iterations converge to some random low value, producing $\chi^{2}$ values far above the potential minimum. Furthermore, it should be noted that the $\mathrm{pH}$ fitting was carried out here on the corresponding $\mathrm{H}^{+}$ concentrations, whereas Jourabchi et al. (2008) used the $\mathrm{pH}$ values instead. $\mathrm{H}^{+}$concentrations offer a far larger dynamical range than $\mathrm{pH}$, thus providing a stronger constraint.

We concur with Jourabchi et al. (2008) in concluding that there are probably other constituents, reactions and processes not considered in our models that may significantly impinge on the proton exchange reactions and thus influence the $\mathrm{pH}$ profiles in a way that thus cannot be reproduced. However, there are additional assumptions that must also be considered to explain the model-data discrepancies. The empirical relationship used to derive the burial rate from the seafloor depth is possibly unreliable for usage at isolated sites. At some stations, a model configuration with a DBL might be required. This is almost certainly the case at site 120 , for which Wenzhöfer et al. (2001) determined a DBL thickness of $725 \pm 25 \mu \mathrm{m}$. $^{6}$

\section{Conclusions}

Version 2 of MEDUSA, the Model of Early Diagenesis in the Upper Sediment with Adaptable complexity, offers a flexible approach to develop tailored sediment modules suitable for coupling to ocean biogeochemical cycle models, but also for process analysis and teaching. MEDUSA is based upon the standard time-dependent diagenetic equation (e.g. Berner, 1980; Boudreau, 1997) with the vertical as the only spatial dimension. The chemical composition of the solid and solute phases can be chosen to fit the requirements of the scientific question to address. The network of diagenetic reactions (redox processes, mineral dissolution, etc.) and chemical equilibria in the pore waters can be made exactly as complex as required. The application programming interfaces (APIs) allow coupling to the most commonly encountered geographical grid layouts in biogeochemical models (unstructured, two-dimensional or hierarchically ordered twodimensional arrays of two-dimensional areas). They have furthermore been designed so that existing model configurations can be easily extended (or simplified). The adopted numerical procedures allow for a large range of time steps, making MEDUSA suitable for long simulation experiments with well-resolved representations of the sea floor (several thousand sediment columns). Parallel processing for multicolumn set-ups is supported via Message Passing Interface (MPI) instructions that can be optionally activated.

Three test case applications have been selected and presented in this model description paper. The first one revisits the study of Munhoven (2007), which used the predecessor version MEDUSA v1. A model configuration with exactly the same functionality as MEDUSA v1 was set up and extended by the age-monitoring facilities offered by MEDUSA. The latter are based upon the Constituent-oriented Age and Residence time Theory, CART (Deleersnijder et al., 2001; Delhez et al., 1999), which has a well-established record in

\footnotetext{
${ }^{6}$ Site 120 is identical to site GeoB4901 in Wenzhöfer et al. (2001)
} 

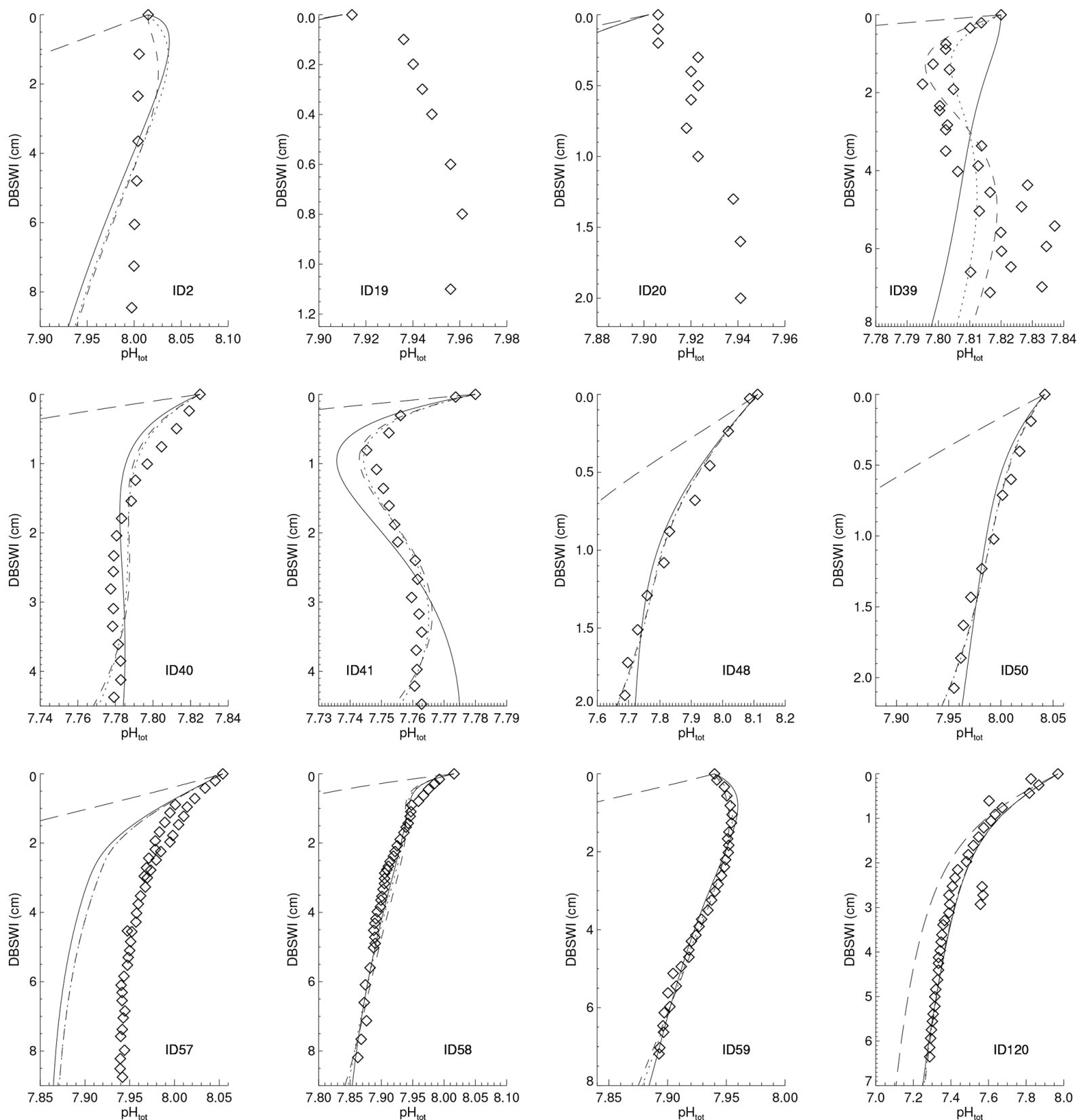

Figure 6. The $\mathrm{pH}$ profiles for experiments with calcite mass fractions in the deposition flux limited to $90 \%$. Lines are as follows: long dashed - no calcite dissolution; full - calcite dissolution kinetics of order 4.5; dotted - order 2; short dashes - linear.

the analysis of geophysical fluid flow models. CART can be easily transposed to the standard equations describing the early diagenesis of sea-floor sediments. The newly generated model code accurately reproduces the original results. The added age control information provides insight into the relationship between the actual time-dependent evolution of the sea-floor sedimentary mixed layer composition and the resulting sedimentary record.

For the second application, a coupling simulator was developed to illustrate the opportunities and to assess the com- putational requirements of using a fully coupled vertically resolved early diagenesis model as the ocean-sediment exchange scheme in a model of ocean biogeochemical cycles. MEDUSA offers attractive flexibility requiring reasonable computational overburden. Parallel processing with MPI allows for a significant gain in computing time. Even fully coupled simulation experiments with a horizontal resolution of $1^{\circ} \times 1^{\circ}$, with of the order of 40000 sea-floor grid points, are conceivable. MEDUSA is thus well suited to upgrade com- 

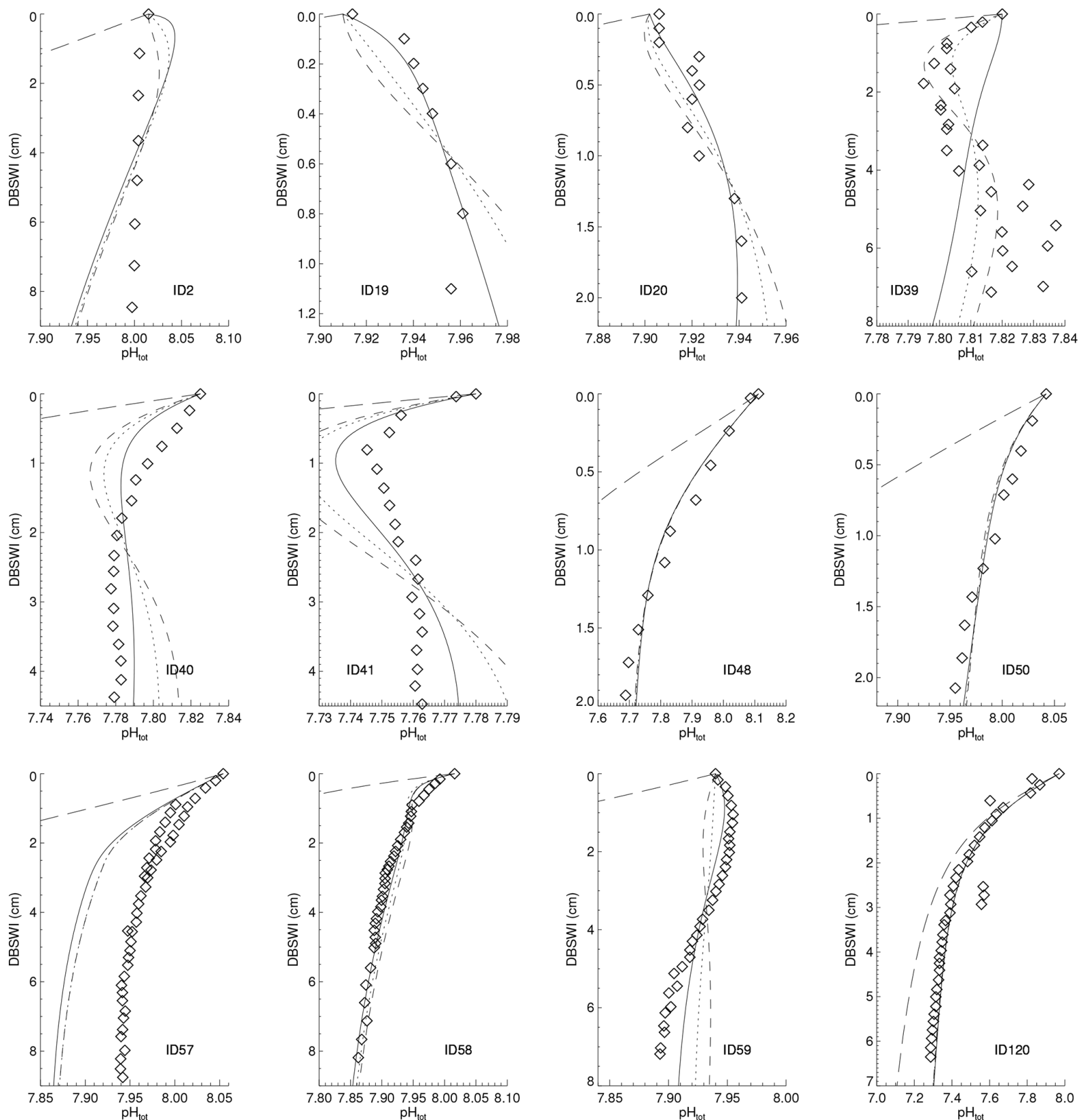

Figure 7. The $\mathrm{pH}$ profiles with data-constrained surface sediment \%Calcite. Lines are as follows: long dashed - no calcite dissolution; full calcite dissolution kinetics of order 4.5; dotted - order 2; short dashes - order 1 (linear). Please note that the $n=4.5$ fit at site 2 and all the fits for sites 19 and 20 require calcite mass fractions in the deposition fluxes exceeding $100 \%$ (between $140 \%$ and $730 \%$ ).

monly used category 1,2 and 3 ocean-sediment exchange schemes in biogeochemical models.

The third application considered a complex composition and reaction network. The performance of MEDUSA was analysed and compared to that of the state-of-the-art early diagenesis model BRNS-global (Jourabchi et al., 2005) by revisiting the study of Jourabchi et al. (2008). In that study, pore-water $\mathrm{O}_{2}$ and $\mathrm{pH}$ microelectrode profiles taken in situ were interpreted with BRNS-global. The results obtained with MEDUSA compare favourably to those obtained by Jourabchi et al. (2008).

Like most models MEDUSA has, and will probably always have, a touch of a "never-ending story". In one of the next stages, adsorption processes will be added to MEDUSACOCOGEN. The currently generated model code can be manually amended or patched to take into account adsorption along the lines developed by Berner (1976). A consistent and mechanistically based approach with as few early- 
stage simplifying assumptions as possible would nevertheless be preferable, and a treatment similar to the solute systems is currently being worked out. It is furthermore planned to improve the computing time requirements by dealing separately with variables that do not have any impact on the solids' advection rate profiles. In general, isotopic signatures, production times and colour tracers range among these variables. This way, the dimensions of the equation system that must be solved for each outer (fixed-point) iteration can be reduced. Currently, the computational demand roughly scales as the square of the number of components considered. Thus, even a $10 \%$ reduction in the number of components to consider for the complete system of equations would reduce the overall computational demand by about $20 \%$. The remaining variables can then be treated without any further outer iterations once the advection rate profile has stabilised.

The numerical efficiency of MEDUSA allows for long simulation experiments required to analyse the dynamics of development of particular sedimentary features that take a long time to develop. Such features show up in steadystate simulations but would go undetected in time-dependent simulation experiments unless run over a sufficiently long time. With interactive sediments, a biogeochemical model generally requires much longer to reach equilibrium (50 to $200 \mathrm{kyr}$ ). Isotope-enabled applications generally range at the upper end of the range. Vertically resolved early diagenesis models are often of similar vertical complexity (in terms of the number of vertical layers) as the biogeochemical models that they are meant to be coupled to. It is therefore important to have a model that offers the possibility of long time steps and that can be trimmed down to the bare essentials required by any given application.

Code availability. The codes used in this paper are provided in the archive included in the Supplement for use under the GNU Affero General Public License version 3 or later (the $\mu$ XML library, MEDUSA, MEDUSACOCOGEN and the MEDUSA applications, including MEDMBM) or the Apache 2.0 license (LIBTHDYCT). That archive also includes the required forcing data, except for the data from the coupling simulator, which have to be downloaded from their original sources. Instructions on how to repeat all the reported simulation experiments are given in the "Building and Running the Test Case Applications" memo in the Supplement. The codes are furthermore archived on Zenodo (Munhoven, 2020a, https://doi.org/10.5281/zenodo.4677682; Munhoven, 2020b, https://doi.org/10.5281/zenodo.4677788; Munhoven, 2020c, https://doi.org/10.5281/zenodo.4677790). Future bug-fix releases and updates will also be archived there.

Supplement. The supplement related to this article is available online at: https://doi.org/10.5194/gmd-14-3603-2021-supplement.
Competing interests. The author declares that there is no conflict of interest.

Acknowledgements. I thank Parisa Jourabchi and Christof Meile for discussions on their working assumptions and for completing the data used in Jourabchi et al. (2008) as well as Keith Moore and his colleagues for making the results of their BEC simulation experiments openly available to the public. The constructive comments and suggestions from the two anonymous reviewers are greatly appreciated and have helped to considerably improve the paper.

Financial support. Financial support for this work was provided by the Belgian Fund for Scientific Research - F.R.S.-FNRS (project SERENATA, grant no. CDR J.0123.19). Guy Munhoven is a Research Associate with the Belgian Fund for Scientific Research F.R.S.-FNRS.

Review statement. This paper was edited by Sandra Arndt and reviewed by two anonymous referees.

\section{References}

Archer, D.: A data-driven model of the global calcite lysocline, Global Biogeochem. Cy., 10, 511-526, https://doi.org/10.1029/96GB01521, 1996a.

Archer, D. and Maier-Reimer, E.: Effect of deep-sea sedimentary calcite preservation on atmospheric $\mathrm{CO}_{2}$ concentration, Nature, 367, 260-263, https://doi.org/10.1038/367260a0, 1994.

Archer, D., Kheshgi, H., and Maier-Reimer, E.: Dynamics of Fossil Fuel $\mathrm{CO}_{2}$ Neutralization by Marine $\mathrm{CaCO}_{3}$, Global Biogeochem. Cy., 12, 259-276, https://doi.org/10.1029/98GB00744, 1998.

Archer, D., Winguth, A., Lea, D., and Mahowald, N.: What Caused the Glacial-Interglacial Atmospheric $p \mathrm{CO}_{2}$ Cycles?, Rev. Geophys., 38, 159-189, https://doi.org/10.1029/1999RG000066, 2000.

Archer, D. E.: Modeling the Calcite Lysocline, J. Geophys. Res., 96, 17037-17050, https://doi.org/10.1029/91JC01812, 1991.

Archer, D. E.: An atlas of the distribution of calcium carbonate in sediments of the deep sea, Global Biogeochem. Cy., 10, 159174, https://doi.org/10.1029/95GB03016, 1996 b.

Archer, D. E., Morford, J. L., and Emerson, S. R.: A model of suboxic sedimentary diagenesis suitable for automatic tuning and gridded domains, Global Biogeochem. Cy., 16, 1017, https://doi.org/10.1029/2000GB001288, 2002.

Arndt, S., Regnier, P., Goddéris, Y., and Donnadieu, Y.: GEOCLIM reloaded ( $\mathrm{v}$ 1.0): a new coupled earth system model for past climate change, Geosci. Model Dev., 4, 451-481, https://doi.org/10.5194/gmd-4-451-2011, 2011.

Berner, R. A.: Inclusion of adsorption in the modelling of early diagenesis, Earth Planet. Sc. Lett., 29, 333-340, https://doi.org/10.1016/0012-821X(76)90137-0, 1976.

Berner, R. A.: Early Diagenesis. A Theoretical Approach, Princeton Series in Geochemistry, Princeton University Press, Princeton, NJ, ISBN 0-691-08258-8, 1980. 
Boudreau, B. P.: On the equivalence of non-local and radialdiffusion models for porewater irrigation, J. Mar. Res., 42, 731735, https://doi.org/10.1357/002224084788505924, 1984.

Boudreau, B. P.: The Mathematics of Tracer Mixing in Sediments: I. Spatially-Dependent, Diffusive Mixing, Am. J. Sci., 286, 161198, https://doi.org/10.2475/ajs.286.3.161, 1986.

Boudreau, B. P.: Asymptotic forms and solutions of the model for silica-opal diagenesis in bioturbated sediments, J. Geophys. Res., 95, 7367-7379, https://doi.org/10.1029/JC095iC05p07367, 1990.

Boudreau, B. P.: Is burial velocity a master parameter for bioturbation?, Geochim. Cosmochim. Ac., 58, 1243-1249, https://doi.org/10.1016/0016-7037(94)90378-6, 1994.

Boudreau, B. P.: A method-of-lines code for carbon and nutrient diagenesis in aquatic sediments, Comput. Geosci., 22, 479-496, https://doi.org/10.1016/0098-3004(95)00115-8, 1996.

Boudreau, B. P.: Diagenetic Models and Their Implementation, Springer-Verlag, Berlin, ISBN 3-540-61125-8, 1997.

Boudreau, B. P.: Mean mixed depth of sediments: The wherefore and the why, Limnol. Oceanogr., 43, 524-526, https://doi.org/10.4319/lo.1998.43.3.0524, 1998.

Brovkin, V., Ganopolski, A., Archer, D., and Munhoven, G.: Glacial $\mathrm{CO}_{2}$ cycle as a succession of key physical and biogeochemical processes, Clim. Past, 8, 251-264, https://doi.org/10.5194/cp-8251-2012, 2012.

Bruckner, T., Bashmakov, I. A., Mulugetta, Y., Chum, H., De la Vega Navarro, A., Edmonds, J., Faaij, A., Fungtammasan, B., Garg, A., Hertwich, E., Honnery, D., Infield, D., Kainuma, M., Khennas, S., Kim, S., Nimir, H. B., Riahi, K., Strachan, N., Wiser, R., and Zhang, X.: Energy Systems, chap. 7, in: Climate Change 2014: Mitigation of Climate Change. Contribution of Working Group III to the Fifth Assessment Report of the Intergovernmental Panel on Climate Change, edited by: Edenhofer, O., Pichs-Madruga, R., Sokona, Y., Minx, J. C., Farahani, E., Kadner, S., Seyboth, K., Adler, A., Baum, I., Brunner, S., Eickemeier, P., Kriemann, B., Savolainen, J., Schlömer, S., von Stechow, C., and Zwickel, T., Cambridge University Press, Cambridge, UK and New York, USA, 2014.

Capet, A., Meysman, F. J. R., Akoumianaki, I., Soetaert, K., and Grégoire, M.: Integrating sediment biogeochemistry into 3D oceanic models: A study of benthic-pelagic coupling in the Black Sea, Ocean Model., 101, 83-100, https://doi.org/10.1016/j.ocemod.2016.03.006, 2016.

Crucifix, M.: Traditional and novel approaches to palaeoclimate modelling, Quaternary Sci. Rev., 57, 1-16, https://doi.org/10.1016/j.quascirev.2012.09.010, 2012.

Deleersnijder, E., Campin, J.-M., and Delhez, E. J. M.: The concept of age in marine modelling - I. Theory and preliminary model results, J. Marine Syst., 28, 2503-2517, https://doi.org/10.1016/S0924-7963(01)00026-4, 2001.

Delhez, E. J. M., Campin, J.-M., Hirst, A. C., and Deleersnijder, E.: Toward a general theory of the age in ocean modelling, Ocean Model., 1, 17-27, https://doi.org/10.1016/S14635003(99)00003-7, 1999.

Dixit, S., Van Cappellen, P., and van Bennekom, A. J.: Processes controlling solubility of biogenic silica and pore water build-up of silicic acid in marine sediments, Mar. Chem., 73, 333-352, https://doi.org/10.1016/S0304-4203(00)00118-3, 2001.
Dunne, J. P., Sarmiento, and Gnanadesikan, A.: A synthesis of global particle export from the surface ocean and cycling through the ocean interior and on the seafloor, Global Biogeochem. Cy., 21, GB4006, https://doi.org/10.1029/2006GB002907, 2007.

Eby, M., Zickfeld, K., Montenegro, A., Archer, D., Meissner, K. J., and Weaver, A. J.: Lifetime of Anthropogenic Climate Change: Millennial Time Scales of Potential $\mathrm{CO}_{2}$ and Surface Temperature Perturbations, J. Climate, 22, 2501-2511, https://doi.org/10.1175/2008JCLI2554.1, 2009.

Eby, M., Weaver, A. J., Alexander, K., Zickfeld, K., Abe-Ouchi, A., Cimatoribus, A. A., Crespin, E., Drijfhout, S. S., Edwards, N. R., Eliseev, A. V., Feulner, G., Fichefet, T., Forest, C. E., Goosse, H., Holden, P. B., Joos, F., Kawamiya, M., Kicklighter, D., Kienert, H., Matsumoto, K., Mokhov, I. I., Monier, E., Olsen, S. M., Pedersen, J. O. P., Perrette, M., Philippon-Berthier, G., Ridgwell, A., Schlosser, A., Schneider von Deimling, T., Shaffer, G., Smith, R. S., Spahni, R., Sokolov, A. P., Steinacher, M., Tachiiri, K., Tokos, K., Yoshimori, M., Zeng, N., and Zhao, F.: Historical and idealized climate model experiments: an intercomparison of Earth system models of intermediate complexity, Clim. Past, 9, 11111140, https://doi.org/10.5194/cp-9-1111-2013, 2013.

Emerson, S.: Organic carbon preservation in marine sediments, in: The Carbon Cycle and Atmospheric $\mathrm{CO}_{2}$ : Natural Variations Archean to Present, edited by Sundquist, E. T. and Broecker, W. S., AGU, Washington, DC, Geophys. Monogr. Ser., 32, 7887, https://doi.org/10.1029/GM032p0078, 1985.

Engeln-Müllges, G. and Uhlig, F.: Numerical Algorithms with Fortran, Springer-Verlag, Berlin, ISBN 3-540-60529-0, 1996.

Ermakov, I., Crucifix, M., and Munhoven, G.: Emulation of the MBM-MEDUSA model: exploring the sea level and the basinto-shelf transfer influence on the system dynamics, EGU General Assembly, Vienna, Austria, 7-12 April 2013, EGU2013-9011-2, available at: https://meetingorganizer.copernicus.org/EGU2013/ EGU2013-9011-2.pdf (last access: 27 May 2021), 2013.

Fiadeiro, M. E. and Veronis, G.: On weighted-mean schemes for the finite difference approximation to the advection-diffusion equation, Tellus, 29, 512-522, https://doi.org/10.3402/tellusa.v29i6.11385, 1977.

Gehlen, M., Bopp, L., Emprin, N., Aumont, O., Heinze, C., and Ragueneau, O.: Reconciling surface ocean productivity, export fluxes and sediment composition in a global biogeochemical ocean model, Biogeosciences, 3, 521-537, https://doi.org/10.5194/bg-3-521-2006, 2006.

Heinze, C. and Maier-Reimer, E.: The Hamburg Oceanic Carbon Cycle Circulation Model Version "HAMOCC2s" for long time integrations, Technical Report 20, Deutsches Klimarechenzentrum, Hamburg (DE), https://doi.org/10.2312/WDCC/DKRZ_Report_No20, 1999.

Heinze, C., Maier-Reimer, E., and Winn, K.: Glacial $\mathrm{pCO}_{2}$ reduction by the World Ocean: Experiments with the Hamburg Carbon Cycle Model, Paleoceanography, 6, 395-430, https://doi.org/10.1029/91PA00489, 1991.

Heinze, C., Maier-Reimer, E., Winguth, A. M. E., and Archer, D.: A global ocean sediment model for long-term climate studies, Global Biogeochem. Cy., 13, 221-250, https://doi.org/10.1029/98GB02812, 1999.

Heinze, C., Kriest, I., and Maier-Reimer, E.: Age offsets among different biogenic and lithogenic components of sediment cores re- 
vealed by numerical modeling, Paleoceanography, 24, PA4214, https://doi.org/10.1029/2008PA001662, 2009.

Hoffert, M. I., Callegari, A. J., and Hsieh, C.-T.: A Box-Diffusion Carbon Cycle Model with Upwelling, Polar Bottom Water Formation and a Marine Biosphere, in: Carbon Cycle Modelling, edited by: Bolin, B., John Wiley \& Sons, Chichester, NY, SCOPE, 16, 285-305, 1981.

Hülse, D., Arndt, S., Wilson, J. D., Munhoven, G., and Ridgwell, A.: Understanding the causes and consequences of past marine carbon cycling variability through models, Earth-Sci. Rev., 171, 349-382, https://doi.org/10.1016/j.earscirev.2017.06.004, 2017.

Hülse, D., Arndt, S., Daines, S., Regnier, P., and Ridgwell, A.: OMEN-SED 1.0: a novel, numerically efficient organic matter sediment diagenesis module for coupling to Earth system models, Geosci. Model Dev., 11, 2649-2689, https://doi.org/10.5194/gmd-11-2649-2018, 2018.

Hundsdorfer, W. and Verwer, J.: Numerical Solution of TimeDependent Advection-Diffusion-Reaction Equations, Springer Series in Computational Mathematics, Springer, Berlin, https://doi.org/10.1007/978-3-662-09017-6, 2003.

Ilyina, T., Six, K. D., Segschneider, J., Maier-Reimer, E., Li, H., and Núñez-Riboni, I.: Global ocean biogeochemistry model HAMOCC: Model architecture and performance as component of the MPI-Earth system model in different CMIP5 experimental realizations, J. Adv. Model. Earth Sy., 5, 287-315, https://doi.org/10.1029/2012MS000178, 2013a.

Ilyina, T., Wolf-Gladrow, D., Munhoven, G., and Heinze, C.: Assessing the potential of calcium-based artificial ocean alkalinization to mitigate rising atmospheric $\mathrm{CO}_{2}$ and ocean acidification, Geophys. Res. Lett., 40, 5909-5914, https://doi.org/10.1002/2013GL057981, 2013b.

Jones, I. W., Munhoven, G., Tranter, M., Huybrechts, P., and Sharp, M. J.: Modelled glacial and non-glacial $\mathrm{HCO}_{3}^{-}, \mathrm{Si}$ and $\mathrm{Ge}$ fluxes since the LGM: little potential for impact on atmospheric $\mathrm{CO}_{2}$ concentrations and a potential proxy of continental chemical erosion, the marine Ge/Si ratio, Global Planet. Change, 33, 139153, https://doi.org/10.1016/S0921-8181(02)00067-X, 2002.

Jourabchi, P., Van Cappellen, P., and Regnier, P.: Quantitative interpretation of $\mathrm{pH}$ distributions in aquatic sediments: A reaction-transport modeling approach, Am. J. Sci., 305, 919956, https://doi.org/10.2475/ajs.305.9.919, 2005.

Jourabchi, P., Meile, C., Pasion, L. R., and Van Cappellen, P.: Quantitative interpretation of pore water $\mathrm{O}_{2}$ and $\mathrm{pH}$ distributions in deep-sea sediments, Geochim. Cosmochim. Ac., 72, 1350-1364, https://doi.org/10.1016/j.gca.2007.12.012, 2008.

Keir, R. S.: Dissolution of calcite in the deep-sea: theoretical prediction for the case of uniform size particles settling into a well-mixed sediment, Am. J. Sci., 282, 193-236, https://doi.org/10.2475/ajs.282.3.193, 1982.

Keir, R. S.: On the Late Pleistocene Ocean Geochemistry and Circulation, Paleoceanography, 3, 413-445, https://doi.org/10.1029/PA003i004p00413, 1988.

Keir, R. S. and Berger, W. H.: Atmospheric $\mathrm{CO}_{2}$ content in the last 120,000 years: The phosphate-extraction model, J. Geophys. Res., 88, 6027-6038, https://doi.org/10.1029/JC088iC10p06027, 1983.

Kurahashi-Nakamura, T., Paul, A., Munhoven, G., Merkel, U., and Schulz, M.: Coupling of a sediment diagenesis model (MEDUSA) and an Earth system model (CESM1.2): a contri- bution toward enhanced marine biogeochemical modelling and long-term climate simulations, Geosci. Model Dev., 13, 825840, https://doi.org/10.5194/gmd-13-825-2020, 2020.

Luff, R. and Moll, A.: Seasonal dynamics of the North Sea sediments using a three-dimensional coupled sedimentwater model system, Cont. Shelf Res., 24, 1099-1127, https://doi.org/10.1016/j.csr.2004.03.010, 2004.

Luff, R., Wallmann, K., Grandel, S., and Schlüter, M.: Numerical modeling of benthic processes in the deep Arabian Sea, DeepSea Res. Pt. II, 47, 3039-3072, https://doi.org/10.1016/S09670645(00)00058-8, 2000.

Maier-Reimer, E.: Towards a global ocean carbon model, in: Interactions between Climate and Biosphere, edited by: Lieth, H., Fantechi, R., and Schnitzler, H., Swets \& Zeitlinger, Lisse, NL, Progress in Biometeorology, 3, 295-310, 1984.

Maier-Reimer, E., Kriest, I., Segschneider, J., and Wetzel, P.: The HAMburg Ocean Carbon Cycle Model HAMOCC 5.1 - Technical Description Release 1.1, Berichte zur Erdsystemforschung [Reports on Earth System Science] 14, Max-Planck-Institut für Meteorologie, Hamburg, DE, https://doi.org/10.17617/2.994983, 2005.

Markwardt, C. B.: Non-linear Least Squares Fitting in IDL with MPFIT, in: Proceedings of Astronomical Data Analysis Software and Systems XVIII, Quebec, Canada, edited by: Bohlender, D., Dowler, P., and Durand, D., Astronomical Society of the Pacific, San Francisco, CA, ASP Conference Series, 411, 251-254, 2009.

Martin, W. R. and Sayles, F. L.: $\mathrm{CaCO}_{3}$ dissolution in sediments of the Ceara Rise, western equatorial Atlantic, Geochim. Cosmochim. Ac., 60, 243-263, https://doi.org/10.1016/00167037(95)00383-5, 1996.

Moore, J. K., Doney, S. C., and Lindsay, K.: Upper ocean ecosystem dynamics and iron cycling in a global threedimensional model, Global Biogeochem. Cy., 18, GB4028, https://doi.org/10.1029/2004GB002220, 2004.

Moore, J. K., Doney, S. C., and Lindsay, K.: The Role of Ecosystem Dynamics on the Global Ocean Carbon Cycle: A JGOFS Model-Data Synthesis, U.S. JGOFS [data set], iPub, available at: http://usjgofs.whoi.edu/mzweb/smpdatadocs/ moore_becmodel.html (last access: 10 January 2020), 2005.

Moore, J. K., Lindsay, K., Doney, S. C., Long, M. C., and Misumi, K.: Marine Ecosystem Dynamics and Biogeochemical Cycling in the Community Earth System Model [CESM1(BGC)]: Comparison of the 1990s with the 2090s under the RCP4.5 and RCP8.5 Scenarios, J. Climate, 26, 9291-9312, https://doi.org/10.1175/JCLI-D-12-00566.1, 2013.

Moreira Martinez, S., Roche, D. M., Munhoven, G., and Waelbroeck, C.: Coupling MEDUSA sediment model to iLOVECLIM (v1.1 $\beta$ ) Earth system model, in: 12th International Conference on Paleoceanography (ICP12), Utrecht, The Netherlands, 29 August 2016-2 September 2016, P-368, available at: http: //hdl.handle.net/2268/219749 (last access: 28 May 2021), 2016.

Munhoven, G.: Modelling Glacial-Interglacial Atmospheric $\mathrm{CO}_{2}$ Variations: The Role of Continental Weathering, $\mathrm{PhD}$ thesis, Université de Liège, Liège, available at: http://hdl.handle.net/ 2268/161314 (last access: 28 May 2021), 1997.

Munhoven, G.: Glacial-interglacial rain ratio changes: Implications for atmospheric $\mathrm{CO}_{2}$ and ocean-sediment interaction, Deep-Sea Res. Pt. II, 54, 722-746, https://doi.org/10.1016/j.dsr2.2007.01.008, 2007. 
Munhoven, G.: Model of Early Diagenesis in the Upper Sediment with Adaptable complexity - MEDUSA (v. 2): a time-dependent biogeochemical sediment module for Earth System Models, process analysis and teaching (Version 2.0), Zenodo [software], https://doi.org/10.5281/zenodo.4677682, 2020a.

Munhoven, G.: The Fortran 95 Library $\mu$ XML, (Version 1.0), Zenodo [software], https://doi.org/10.5281/zenodo.4677788, $2020 \mathrm{~b}$.

Munhoven, G.: THDYCT (THermoDYnamic ConsTants) - a legacy FORTRAN 77 library for carbonate system speciation calculations, Zenodo [software], https://doi.org/10.5281/zenodo.4677790, 2020c.

Munhoven, G. and François, L. M.: Glacial-interglacial variability of atmospheric $\mathrm{CO}_{2}$ due to changing continental silicate rock weathering: A model study, J. Geophys. Res., 101, 21423-21437, https://doi.org/10.1029/96JD01842, 1996.

Palastanga, V., Slomp, C. P., and Heinze, C.: Long-term controls on ocean phosphorus and oxygen in a global biogeochemical model, Global Biogeochem. Cy., 25, GB3024, https://doi.org/10.1029/2010GB003827, 2011.

Ridgwell, A.: Interpreting transient carbonate compensation depth changes by marine sediment core modeling, Paleoceanography, 22, PA4102, https://doi.org/10.1029/2006PA001372, 2007.

Ridgwell, A. and Hargreaves, J. C.: Regulation of atmospheric $\mathrm{CO}_{2}$ by deep-sea sediments in an Earth system model, Global Biogeochem. Cy., 21, GB2008, https://doi.org/10.1029/2006GB002764, 2007.

Schink, D. R. and Guinasso Jr., N. L.: Modelling the Influence of Bioturbation and Other Processes on Calcium Carbonate Dissolution at the Sea Floor, in: The Fate of Fossil Fuel $\mathrm{CO}_{2}$ in the Oceans, edited by: Andersen, N. R. and Malahoff, A., Plenum Press, New York, NY, 375-399, 1977.

Seiter, K., Hensen, C., Schröter, J., and Zabel, M.: Organic carbon content in surface sediments-defining regional provinces, Deep-Sea Res. Pt. I, 51, 2001-2026, https://doi.org/10.1016/j.dsr.2004.06.014, 2004.

Shaffer, G., Malskær Olsen, S., and Pepke Pedersen, J. O.: Presentation, calibration and validation of the low-order, DCESS Earth System Model (Version 1), Geosci. Model Dev., 1, 17-51, https://doi.org/10.5194/gmd-1-17-2008, 2008.

Sigman, D. M., McCorkle, D. C., and Martin, W. R.: The calcite lysocline as a constraint on glacial/interglacial low-latitude production changes, Global Biogeochem. Cy., 12, 409-427, https://doi.org/10.1029/98GB01184, 1998.

Soetaert, K., Herman, P. M. J., and Middelburg, J. J.: A model of early diagenetic processes from the shelf to abyssal depths, Geochim. Cosmochim. Ac., 60, 1019-1040, https://doi.org/10.1016/0016-7037(96)00013-0, 1996.

Soetaert, K., Middelburg, J. J., Herman, P. M. J., and Buis, K.: On the coupling of benthic and pelagic biogeochemical models, Earth-Sci. Rev., 51, 173-201, https://doi.org/10.1016/S00128252(00)00004-0, 2000.
Sulpis, O., Boudreau, B. P., Mucci, A., Jenkins, C., Trossman, D. S., Arbic, B. K., and Key, R. M.: Current $\mathrm{CaCO}_{3}$ dissolution at the seafloor caused by anthropogenic $\mathrm{CO}_{2}$, P. Natl. Acad. Sci. USA, 115, 11700-11705, https://doi.org/10.1073/pnas.1804250115, 2018.

Sundquist, E. T.: Geologic Analogs: Their Value and Limitations in Carbon Dioxide Research, in: The Changing Carbon $\mathrm{Cy}-$ cle: A Global Analysis, edited by: Trabalka, J. R. and Reichle, D. E., Springer-Verlag, New York (NY), chap. 19, 371-402, https://doi.org/10.1007/978-1-4757-1915-4_19, 1986.

Taylor, K. E.: Summarizing multiple aspects of model performance in a single diagram, J. Geophys. Res., 106, 7183-7192, https://doi.org/10.1029/2000JD900719, 2001.

Tschumi, T., Joos, F., Gehlen, M., and Heinze, C.: Deep ocean ventilation, carbon isotopes, marine sedimentation and the deglacial $\mathrm{CO}_{2}$ rise, Clim. Past, 7, 771-800, https://doi.org/10.5194/cp-7771-2011, 2011.

Van Cappellen, P. and Wang, Y.: Cycling of Iron and Manganese in Surface Sediments: A General Theory for the Coupled Transport and Reaction of Carbon, Oxygen, Nitrogen, Sulfur, Iron, and Manganese, Am. J. Sci., 296, 197-243, https://doi.org/10.2475/ajs.296.3.197, 1996

Völker, C., Ye, Y., Butzin, M., Köhler, P., and Munhoven, G.: Role of sediment in the marine $\mathrm{C}$ cycle-insights from a coupled oceansediment model, EGU General Assembly 2020, Online, 4-8 May 2020, EGU2020-18562, https://doi.org/10.5194/egusphereegu2020-18562, 2020.

W3C: Extensible Markup Language (XML) 1.0 (Fifth Edition), W3C recommendation 26 November 2008, W3C, available at: http://www.w3.org/TR/2008/REC-xml-20081126 (last access 2 February 2017), 2008.

Walker, J. C. G. and Opdyke, B. C.: Influence of variable rates of neritic carbonate deposition on atmospheric carbon dioxide and pelagic sediments, Paleoceanography, 10, 415-427, https://doi.org/10.1029/94PA02963, 1995.

Wenzhöfer, F., Adler, M., Kohls, O., Hensen, C., Strotmann, B., Boehme, S., and Schulz, H.: Calcite dissolution driven by benthic mineralization in the deep-sea: In situ measurements of $\mathrm{Ca}^{2+}$, pH, $\mathrm{pCO}_{2}$ and $\mathrm{O}_{2}$, Geochim. Cosmochim. Ac., 65, 2677-2690, https://doi.org/10.1016/S0016-7037(01)00620-2, 2001.

Yool, A., Popova, E. E., and Anderson, T. R.: Medusa-1.0: a new intermediate complexity plankton ecosystem model for the global domain, Geosci. Model Dev., 4, 381-417, https://doi.org/10.5194/gmd-4-381-2011, 2001.

Zickfeld, K., MacDougall, A. H., and Matthews, H. D.: On the proportionality between global temperature change and cumulative $\mathrm{CO}_{2}$ emissions during periods of net negative $\mathrm{CO}_{2}$ emissions, Environ. Res. Lett., 11, 055006, https://doi.org/10.1088/17489326/11/5/055006, 2016. 